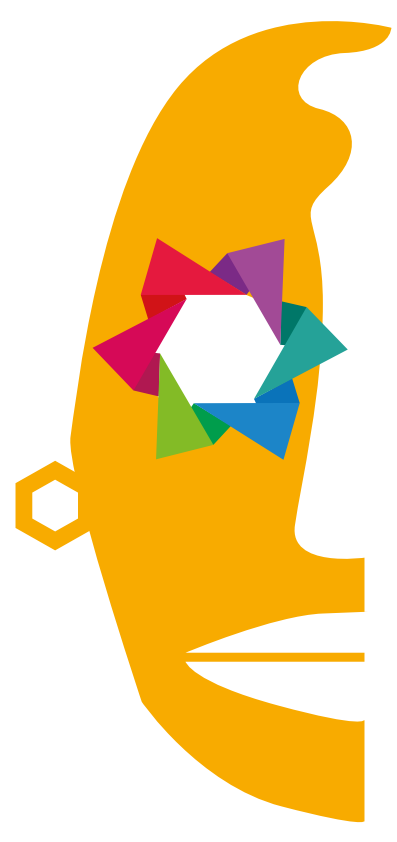

María Luisa Herrera Rapela Artista Independiente, sin afiliación institucional Costa Rica-Alemania

\title{
Testimonio: María Rapela, una artista costarricense en Berlín
}

\section{RESUMEN}

Testimonio que recoge algunas experiencias y reflexiones de la artista visual costarricense María Rapela en Alemania y de cómo se involucró en la gestión cultural, coordinando el Fieber Festival, una plataforma colaborativa y auto-gestionada de mujeres artistas migrantes iberoamericanas en Berlín entre el 2011 y el 2017.

Palabras clave: María Rapela, arte, migración, mujeres, Costa Rica, Alemania, Fieber Festival

\section{Abstract}

A testimony that collects some experiences and reflections of the Costa Rican visual artist María Rapela in Germany and how she got involved in cultural management, coordinating the Fieber Festival a collaborative and self-managed platform of Ibero-American migrant women artists in Berlin between 2011 and 2017.

Keywords: María Rapela, art, migration, women, Costa Rica, Germany, Fieber Festival

\section{Se podría decir que las cosas fluyen...}

La vida a veces son idas y vueltas, grandes y pequeños saltos. Por una exposición que realicé en la Alianza Francesa de San José en el 2004, logré sumarme ese mismo año a otra exposición en Lyon. En aquel viaje estuve en algunas ciudades europeas. Con una carpeta de dibujos en la mochila y un rollo de telas en un tubo, mostraba mis trabajos y me definía ante el mundo como artista plástica, 
para ese entonces ya tenía 10 años de pintar y crear. Pensaba que de esa manera conseguiría una exposición o que alguien compraría mis trabajos. En cada ciudad que visitaba, recorría los museos, o buscaba ponerme en contacto con la vida cultural local. Logré un par de citas con galerías y varios rechazos.

Se podría decir que las cosas fluyen cuando una cosa lleva a la otra. Durante ese viaje que inesperadamente me llevó hasta Berlín, no conseguí ningún contrato con galerías, pero conocí al que hoy es mi pareja. Después de una larga relación a distancia nos casamos y, en el 2008, sin saber a ciencia cierta si era por un tiempo o para siempre, me trasladé a Berlín. Hoy, 13 años después, siento que aquí está mi casa, si bien la mitad de mi corazón se quedó para siempre en Costa Rica.

Desde niña asistí a varios talleres de arte, pero fue en 1994, cuando empecé a asistir al taller del argentino Eduardo Barracosa, que empecé a percibir como una realidad tangible la idea de seguir el camino de las artes plásticas. En ese taller que funcionó por más de tres décadas pasaron en algún momento de sus vidas artistas locales como Ulises Jiménez, Federico Herrero, Rocío Con, Josefa Richard, Esteban Calvo, Maricel Alvarado, Antoinette Bourcart, Cristina Gutiérrez, María José Acosta y María José Monge, entre otras personas. En ese período formativo fui becada, trabajé e investigué mucho, compartía con las compañeras del taller, leía libros de arte que circulaban en el taller o en las librerías y asistía a las exposiciones que se realizaban en San José, donde había una pequeña pero inquieta escena artística y cultural. En edad de ir a la universidad estudié Antropología en vez de Artes Plásticas y no sé si he logrado encontrar una unión entre ambas disciplinas, pero ambas están definitivamente integradas en mi visión del mundo $\mathrm{y}$ en mi forma de ver la vida.

\section{Primeros tiempos en Berlín: perderse y encontrarse, el extravío en la migración}

La prepotencia de la juventud nos empuja a actuar y a no pensar tanto en las posibles consecuencias de las decisiones. No es lo mismo ser turista que mudarse a vivir a otro país. Realmente no sospechaba a lo que me enfrentaría al dejar el lugar donde había nacido y alejarme de las personas y lugares que hasta entonces habían configurado mi mundo. Sabía que extrañaría, pero no sabía que el proceso migratorio podía llegar a ser tan doloroso.

No tenía planes claros de cómo ni de qué iba a vivir, pero sabía que tenía que estudiar alemán, buscar trabajo y ponerme a pintar. Llegué motivada y con ganas de ser, luchar, crear, con la juventud y la fuerza de los 28 años. Los primeros años fueron muy productivos a nivel artístico, pero a la vez, muy difíciles por el shock cultural. 
Figura 1. Artista: María Rapela, Encierro invernal, acrílico sobre tela, 90 x 90 cm, 2009

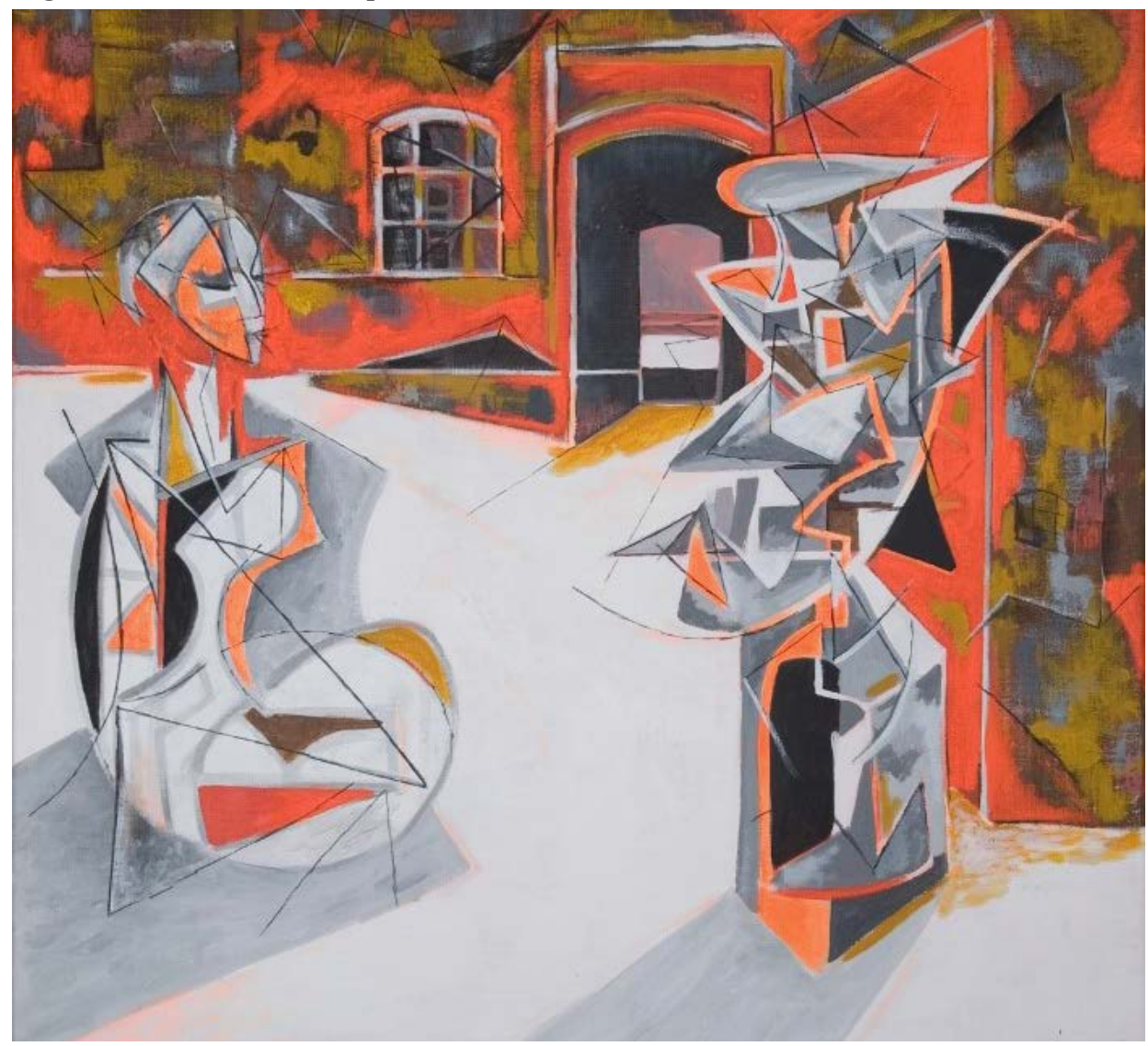

Fuente: María Rapela

Durante los primeros meses de haber llegado me despertaba en la habitación con la sensación de extravío. No entendía que hacía en ese lugar, todo me era ajeno. Afuera una ciudad vibraba con ritmos y sonidos propios. Por mucho tiempo estuve reconstruyendo los caminos, las personas, los sucesos y los acontecimientos precisos que hicieron que yo me encontrara en ese lugar. Hay decisiones, eventos y personas que, unidos, de manera caótica e imprevista, marcan un antes y un después en la vida.

Durante el primer año desarrollé una serie de acrílicos relacionados con la idea de ciudad, de entramado urbano. En mi mente necesitaba reconstruir visualmente la idea de territorio, de mapa, de lugar, de casa. ¿Cómo integrarse en el nuevo contexto, en un nuevo paisaje donde no hay nada que me sea familiar? ¿Dónde quedaron las montañas que arropaban mi ciudad, la luz y los colores que acostumbraron mi pupila? 
Figura 2. Artista: María Rapela, Entramado urbano, acrílico sobre tela, 90 x 90 cm, 2008

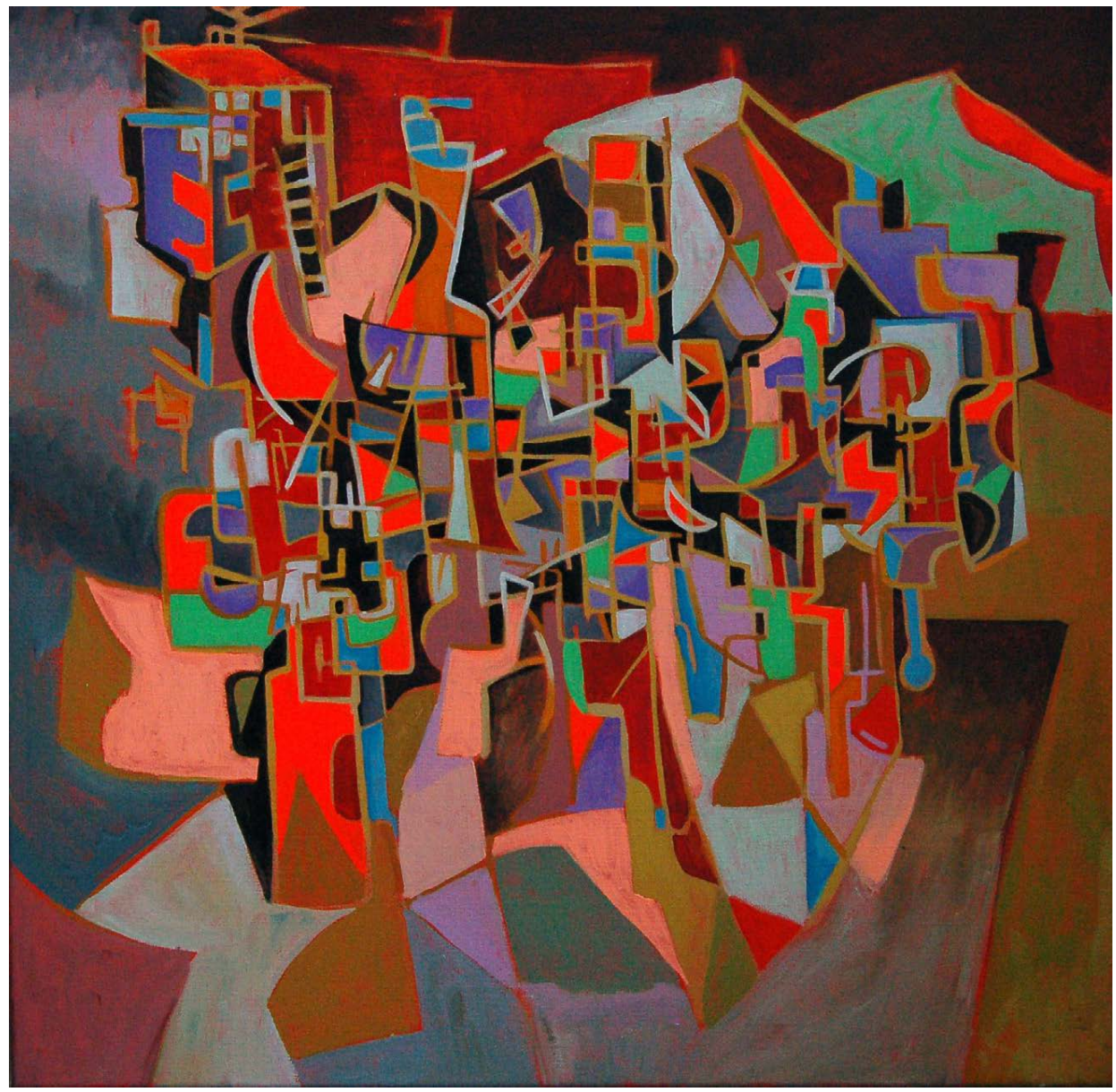

Fuente: María Rapela 
María Luisa Herrera Rapela

Testimonio: María Rapela, una artista costarricense en Berlín

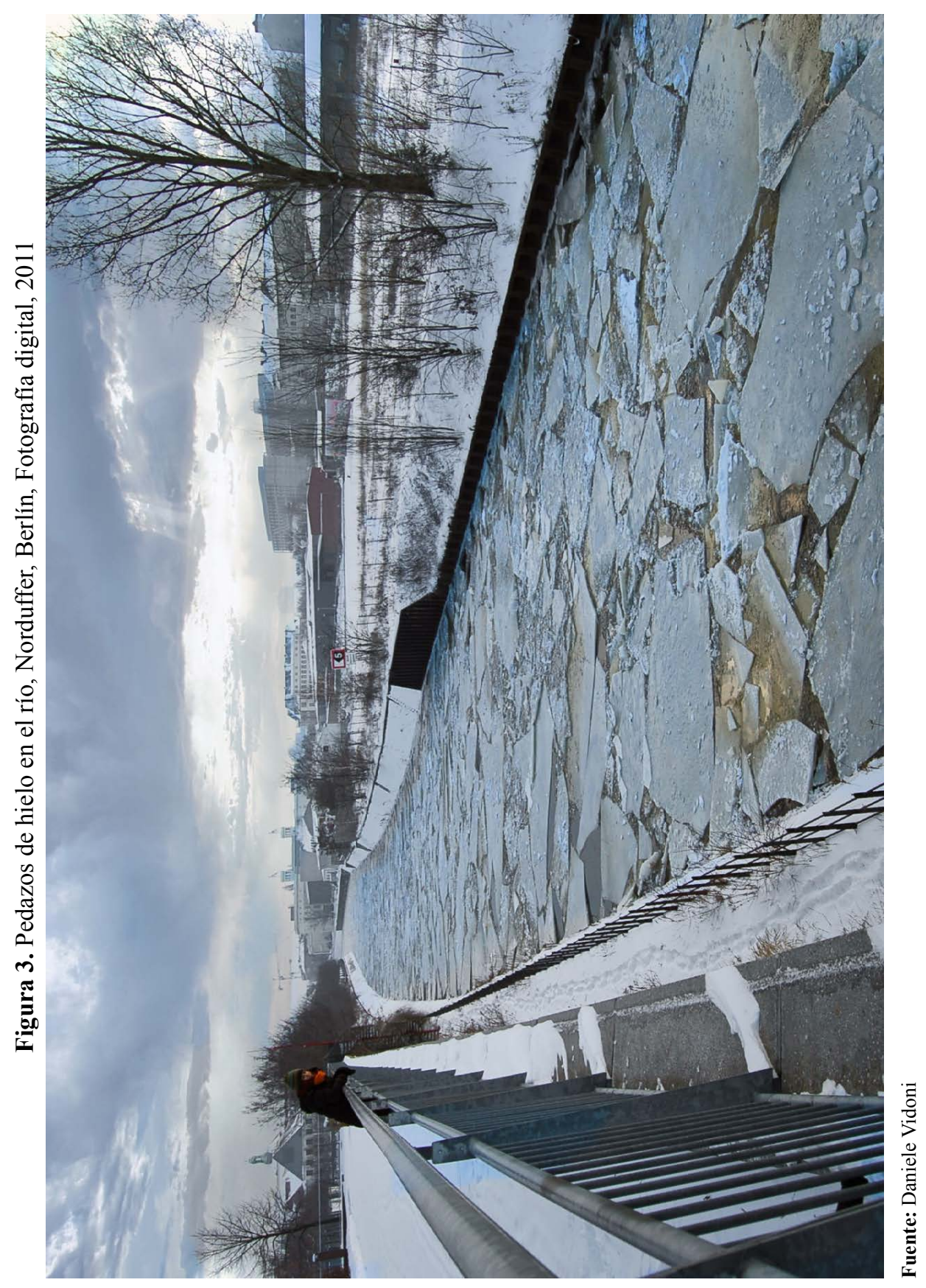


Figura 4. Artista: María Rapela, Pedazos de hielo flotando, acrílico sobre tela, $90 \times 90 \mathrm{~cm}, 2009$

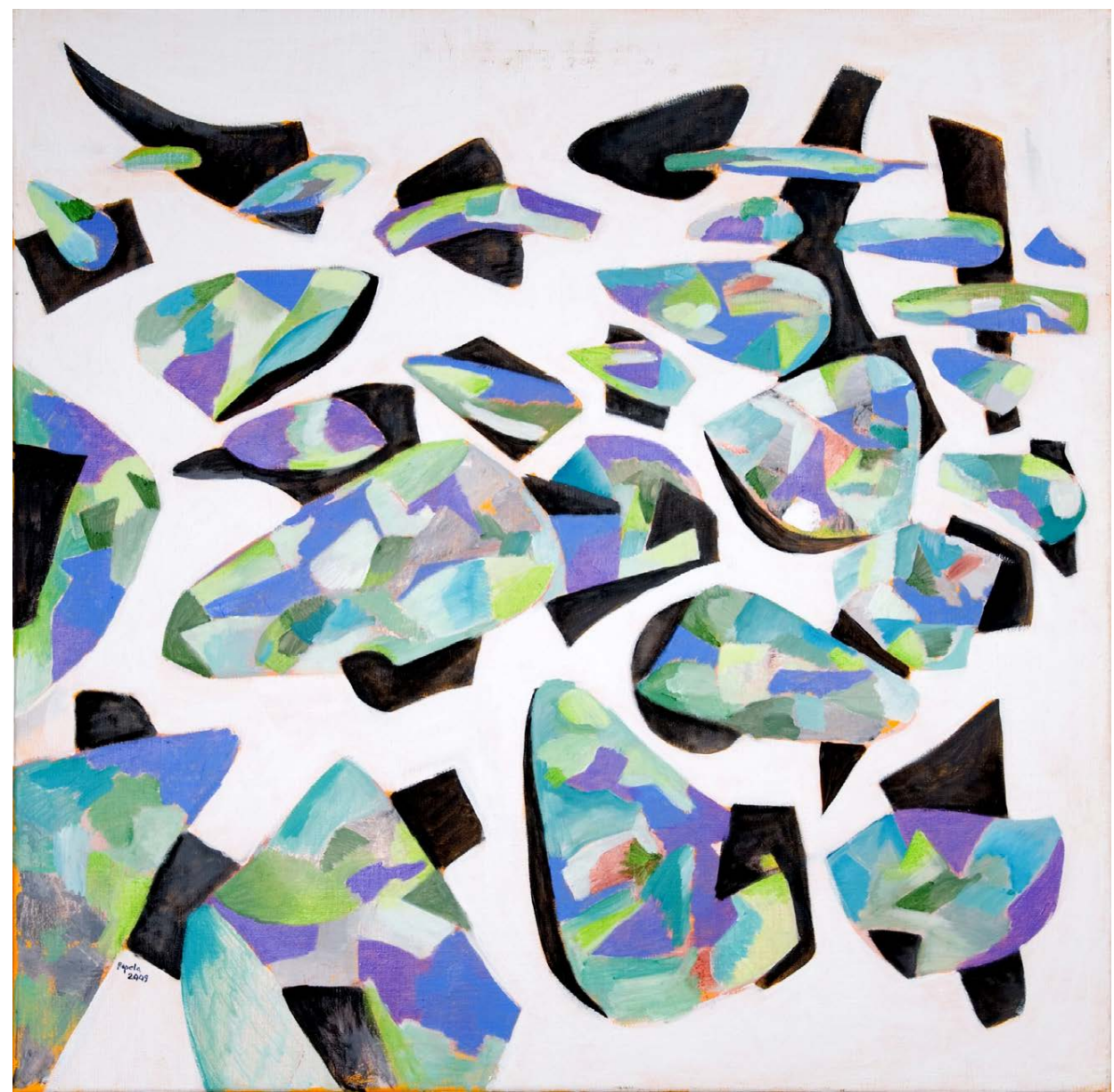

Fuente: María Rapela

Dicen que no se valoran las cosas hasta que se pierden. Todo lo que había formado parte de mi vida hasta entonces y que conformaba mi universo, ya no estaba. Mucho tiempo después entendí, al recordar las ideas del mapa psico-geográfico de la Internacional Situacionista (Debord 1999) ${ }^{1}$ que la única manera de apropiarse y sentirse parte del nuevo territorio, es cargarlo de nuevas historias, relatos, personas y acontecimientos. Con solo el hecho de vivir, se crean marcas, recuerdos y puntos de referencia personales o colectivos, pero eso requiere de paciencia y dejar que el tiempo fluya como las aguas de un río.

1 Guy Debord, "Teoría de la deriva", en $\mathrm{N}^{\circ} 2$ de Internationale Situationniste. Traducción extraída de Internacional situacionista, vol. I: La realización del arte (Madrid: Literatura Gris, 1999). 
Una experiencia durante los días más fríos del invierno, al caminar a lo largo de un río que se descongelaba y observar los pedazos de hielo que flotaban y se desplazaban lentamente, me inspiró a trabajar en el cuadro "Pedazos de hielo flotando", en una serie de trabajos sobre la naturaleza y paisaje urbano, pero a la vez, la idea de fragmentación (de identidades). Quería representar la sensación de fragilidad, la soledad, el individualismo, el abandono. Pude llegar a entender lo que significa sentirse arrojada en el mundo en carne propia, el "Dasein" de Heidegger.

Figura 5. Paseo a la orilla del río. Arrojada en el mundo, Berlín, Fotografía digital, 2011

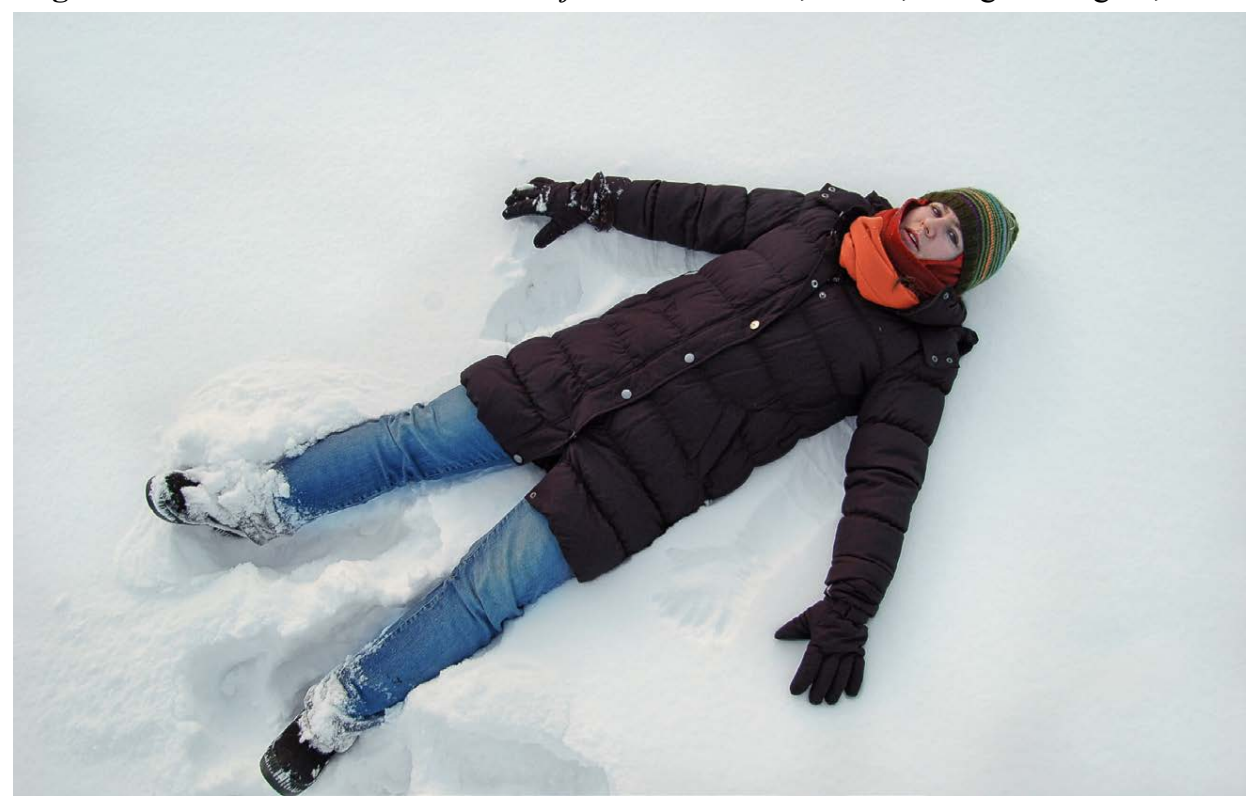

Fuente: Daniele Vidoni

El tiempo pasa y poco a poco se logra crear un entorno más familiar, se cultivan amistades y se hilvanan nuevas historias. Sentía que la mayoría de las puertas estaban cerradas, aún así traté de mantener un espíritu optimista, continuaba tratando de descifrar el funcionamiento del mundo del arte. Hay que hacerse fuerte a tantos rechazos.

\section{Berlín y su panorama artístico}

Cuando asistía a exposiciones o ferias de arte observaba un panorama cultural amplio y variado. Me parecía que había poca pintura, salvo en los museos clásicos y algunas galerías más "tradicionales". Tuve que abrir los ojos para entender que el mundo del arte es mucho más diverso del que yo conocía. Sentía que estaba en la ciudad o quizás en un tiempo equivocado y que aquí la historia del arte iba a otra velocidad y con otros intereses. 
En Berlín, por haber estado dividida durante muchos años, hay dos de cada cosa: dos zoológicos, dos óperas, dos estadios de fútbol y, también, hay dos universidades de Arte (UDK y Weissensee). Hay varias escuelas e institutos privados de arte y edificios enteros con talleres para artistas, algunos semi-financiados por la ciudad, sin embargo, muchos de estos espacios han ido desapareciendo con el tiempo, por la presión que existe sobre la vivienda, así como debido a la especulación inmobiliaria, por lo que no es tan fácil conseguirlos.

En Berlín confluyen artistas establecidos y larga trayectoria, con jóvenes, estudiantes, amateurs. Hay artistas principalmente de Alemania y Europa, pero también del resto del mundo. Si se compara con la naturaleza en Costa Rica, donde hay una gran bio-diversidad, en Berlín existe un ecosistema social, cultural y artístico muy diverso. Como centro de producción (y quizás no tanto como mercado final) ${ }^{2}$ hay de todo y para todos los gustos, aquí he llegado a la conclusión de que, así como hay artistas, hay infinidad de búsquedas.

No he logrado entender del todo cómo funciona el sistema del arte y no sé si algún día lo terminaré de entender, pero creo que se privilegia a las personas innovadoras que ofrecen nuevas perspectivas y combinan una variedad de saberes y técnicas, quienes tienen estudios universitarios, buenos contactos y saben moverse, quienes poseen apoyo económico de algún tipo y quienes generan una visión clara de lo que quieren, pero que además tienen el know-how y el acompañamiento de cómo funcionan los negocios y el marketing en el mundo del arte.

2 Se dice que después de la caída del muro (1989), gracias a los bajos alquileres, Berlín empezó a atraer a una gran cantidad de artistas a vivir, principalmente por la cantidad de espacios vacíos disponibles y porque los alquileres eran muy bajos. Los artistas se podían permitir pasar menos tiempo pensando en hacer dinero y más tiempo creando. Tendencia que ha cambiado radicalmente en los últimos años 2010-2020, donde cada vez es más difícil encontrar si acaso un lugar de vivienda debido a la alta demanda. Los precios han aumentado considerablemente, lo cual ha llevado a la municipalidad a proponer un techo en la subida de los precios para evitar la especulación inmobiliaria. Muchos espacios y talleres de artistas también se han ido cerrando o vendiendo. Para la mayoría, cada vez es más difícil lidiar entre la necesidad de hacer dinero y el tiempo para el trabajo artístico. 
Figura 6. María Rapela en la Feria de arte Berliner Liste, Kraftwerk, Fotografía digital, 2012

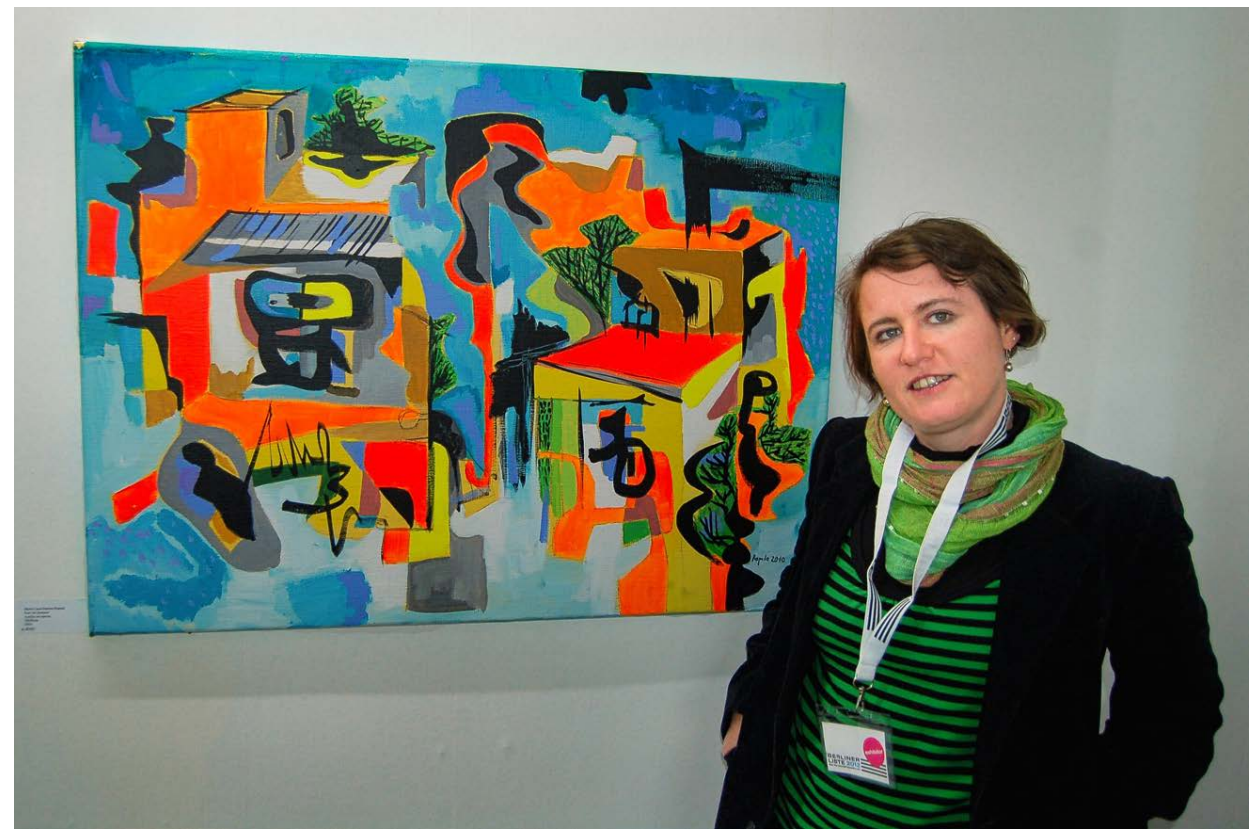

Fuente: Daniele Vidoni

En Berlín hay artistas que funcionan como empresas y tienen 20 ó 50 personas en diferentes áreas trabajando para ellas. Existe también una multitud de artistas en solitario, de todas las edades y proveniencias, trabajando lentamente en sus talleres o casas cuando pueden, desarrollando sus obras, uniéndose en colectivos o grupos, creando dinámicas y situaciones.

De Latinoamérica viene una gran cantidad de artistas por turismo, residencias artísticas temporales, para hacer algún posgrado, curso de arte o exposición, por pareja, familia, antepasados o por mera aventura.

Me parece que existe una idea (en las personas artistas) o una especie de mandato cultural de que hay que ir a las grandes capitales del arte; New York, Londres, Miami, Madrid, Basel, Tokyo, Ciudad de México o Sao Paulo (entre otras), para validarse, ampliar el currículum o simplemente porque allí están los grandes mercados del arte, los coleccionistas, los grandes museos y una gran cantidad artistas. Berlín es hoy uno de esos polos de atracción de artistas por sus espacios y alquileres baratos (cada vez más inaccesible) si bien no es un buen mercado de arte (Wirnshofer) ${ }^{3}$.

3 Wirnshofer, Josef. "Berlin ist die Stadt des Diskurses", Entrevista a Marke Cruse, directora de la Feria de Arte ABC y Berlin Art Week, spiegel.de, 2016. https://www.spiegel.de/kultur/gesellschaft/art-berlin-contemporary-berlin-ist-die-stadt-des-diskurses-a-1112140.html (consultado 25-01-2021) 


\section{Primeras experiencias exponiendo}

Tres años después de haber llegado conseguí exponer en una galería alternativa. Luego vendrían otras oportunidades, unas más interesantes que otras, sin embargo, había algo que me desmotivaba en general y era que todo requería de mucho esfuerzo, recursos, tiempo, creatividad, organización y no se lograba recuperar nada económicamente. Todo eran gastos y pérdidas económicas. En Costa Rica había expuesto en espacios institucionales o centros culturales donde tenían presupuesto para diseño, flyers y generalmente hacían algún trabajo de prensa, aunque siempre me he movido por mi parte. Aquí yo tenía que hacer todo y era poca la gente que llegaba.

También sentía que en estas ciudades grandes la gente tiene tantos estímulos y opciones que no se valoran las cosas de la misma manera que en países pequeños o ciudades secundarias o medias. De igual forma era apabullante ver como las artes visuales empezaban a aparecer en el mar infinito de internet. En un momento dado tuve que bajar el arte del lugar elevado o sacralizado donde lo tenía. En ciudades como estas te podés motivar por la ebullición que te rodea, pero también te pueden lanzar y sentir que no vas a ningún lado. Hay que aprender a luchar y a seguir tu camino, sin distraerte demasiado y sentir que tu voz es tan importante como cualquier otra.

En el 2012 logré entrar a una importante feria de arte, la Berliner Liste, pero no con una galería, sino yo sola como artista, pensé que me abriría nuevas puertas. La gente pasaba, tomaba fotos a mis trabajos, tuve algunas conversaciones interesantes, conocí a otras personas artistas, pero al igual que yo, la mayoría de artistas que conocí, no vendieron nada. Había gente que había venido de otros países, que habían pagado altas sumas de transporte y de estadía y no había logrado recuperar la inversión. A veces pienso que quizás eran malos momentos, la crisis del 2008-2012 golpeó fuerte en Europa y el mundo en general. Pero hoy entiendo que vender es un arte en sí mismo.

En un momento determinado, entré en una especie de depresión artística y dejé de producir con asiduidad, mi casa-taller estaba llena de obra y no sabía ni dónde meterla, tampoco lograba exponerla toda conforme producía. No entendía cuál era el camino y estaba convencida de que nunca podría llegar a vivir de mi trabajo y que siempre tendría que realizar trabajos alternativos y mal pagados para pagar las cuentas. Sentía que todo había sido una gran equivocación y me reprochaba el haberme metido en el camino del arte.

Según un estudio sobre la situación de los artistas plásticos/visuales del 2018, hay alrededor de 8000 artistas visuales en Berlín y solo alrededor del $24 \%$ de artistas hombres y $19 \%$ de mujeres logran cubrir casi al $100 \%$ sus gastos anuales 
de manutención (IFSE) ${ }^{4}$. ¿Cómo vivir del arte o cómo vivir con arte?, ¿Cómo sobrevivir creando y no morir en el intento? Muchas veces las cosas no funcionan como queremos, luchamos y las cosas salen como pueden, como les da la gana.

Pero nada era tan grave, había que aceptar lo que la vida me ofrecía en ese momento, tenía un trabajo, amigas, leía, escribía en mi blog una Tica en Berlín, reflexionaba, colaboraba con otros proyectos, trataba de entender el contexto en el cual estaba inmersa y me enteraba de temas como el de la gentrificación y de cómo las personas artistas han sido utilizadas para hacer de la ciudad un espacio más interesante y dinámico, para acelerar procesos en donde las principales ganadoras son las inmobiliarias.

Un movimiento de artistas de la escena independiente (Coalición de la escena artística independiente, $)^{5}$ dio la lucha para que un porcentaje de las ganancias de una nueva tasa turística que se cobraría a los hoteles (impuesto al hospedaje) se repartiera en proyectos que beneficiaran a la escena de artistas independientes. El discurso era que las personas de la escena artística independiente trabajan muchas veces por poco o nada, haciendo de la ciudad un lugar interesante y dinámico, que atrae turistas, crea nuevas dinámicas, hace que la gente salga de sus casas, que tome un taxi o tren, reserve hoteles o salga de copas por la noche. Por otro lado, están las grandes instituciones burocráticas del arte, como museos, teatros de la ciudad, galerías comunales, óperas, entre otros, que están financiadas por el estado y consumen gran parte del presupuesto cultural. Entonces, se denunciaba la desigualdad en la repartición de los fondos y se exigía más apoyo para la escena independiente, algo así como una lucha de clases entre clases artísticas y creativas.

\section{El Fieber Festival ${ }^{6}$}

Un día apareció una convocatoria para artistas iberoamericanas en Berlín. Acudí al llamado y Lucía González, la fundadora, me indicó: “-No hay nada listo, hay que organizarlo". No tenía mucho interés de entrar en la organización y en la gestión de eventos, pero al final me convencí de que podía ser una nueva experiencia, que no tenía nada que perder. Sin saber que ese Festival cambiaría mi vida en los siguientes años terminé co-organizando el 1er Fieber. Fue así como en el 2011 nació un festival multidisciplinario, auto-gestionado, solidario y colaborativo organizado por mujeres, artistas iberoamericanas residentes en Berlín.

4 Hergen Wöbken, Studio Berlin III Situation Berliner Künstler*innen und Gender Gap (Estudio III sobre la situación de los artistas en Berlin y la brecha de género) (https://ifse.de/Pdf/IFSE_Studio-Berlin-III.pdf, Alemania, Institut für Strategieentwicklung IFSE, 2018).

5 Die Koalition der Freien Szene, Bündnis Freie Szene Berlin e.V. koalition-der-freien-szene-berlin.de (Pressemitteilung vom Comunicado de prensa del 03.04.2012), (Consultado: 25-01-2021)

6 fieberfestival.com Festival Independiente de Artistas Iberoamericanas en Berlín. 2011-2017, (consultado 25-01-2021) 
Figura 7. Cartel 1era edición del Fieber Festival

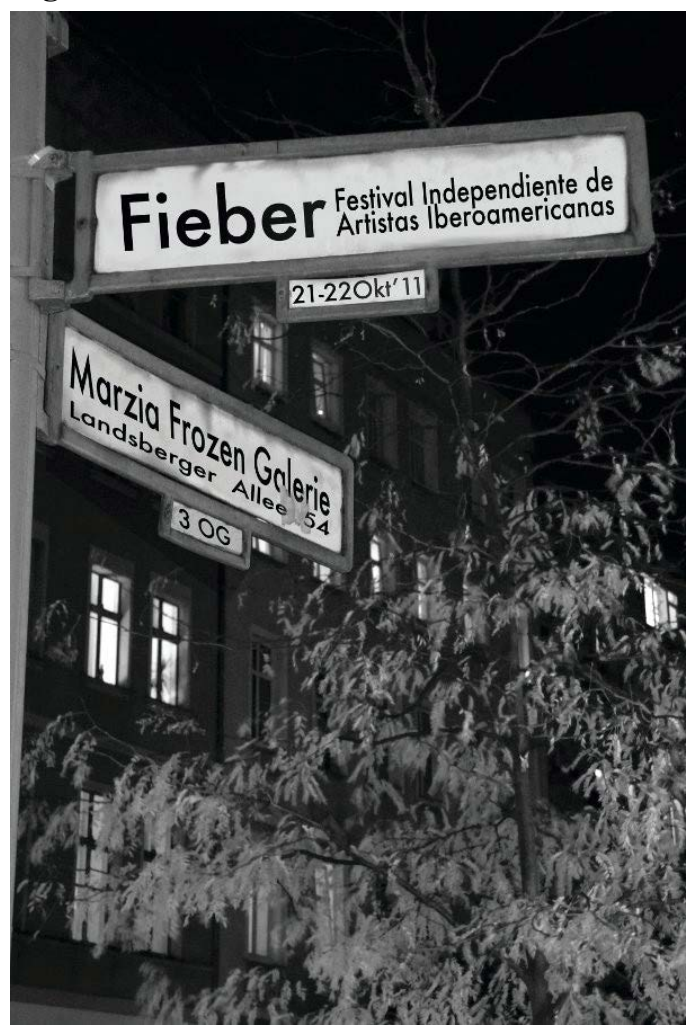

Fuente: Fieber Festival 2011, diseño: Diana Toledo (Latole)
En el primer encuentro de artistas propuse un primer texto de lo que significaba el Fieber, lo leí en voz alta ante las otras artistas para debatir las ideas y recuerdo que todas aportaron un granito, una idea, una visión, haciendo que el texto tuviera una visión más positiva y empoderadora. El lenguaje utilizado de manera consciente puede ser un arma muy poderosa.

Entre Lucía, las otras chicas y yo logramos escribir el siguiente texto, que dice:

"El Festival Independiente de Artistas Iberoamericanas en Berlín -FIEBER-, que se celebrará por primera vez el 21 y 22 de octubre del 2011 en la Galería Marzia Frozen, contará con la participación de más de 30 mujeres creadoras provenientes de toda Iberoamérica y residentes en Berlín.

Las participantes del FIEBER nos hemos reunido y organizado para darle vida a este festival, cuyo propósito es el de crear un espacio de inclusión para las mujeres en el que puedan expresarse y compartir su arte. Además, consideramos el surgimiento de este espacio como el momento oportuno para promover el intercambio, la solidaridad y la cooperación mutua, pues estimamos importante y necesario reafirmar nuestra presencia en el amplio mundo artístico de Berlín.

Conscientes de nuestras variadas experiencias de vida, matizadas de retos y logros, y aprovechando el heterogéneo ensamble que resulta de los diferentes contextos culturales que cada una de nosotras ha traído consigo, afirmamos que la rica mezcla de culturas provoca, estimula y da paso a la creatividad. Poder movernos en el entorno berlinés es también una oportunidad para expandir nuestros horizontes y seguir generando movimiento. Así que desde las diferentes áreas de las artes (artes plásticas, pintura, fotografía, danza, literatura, música, performance, diseño, etc.), queremos mostrar que no solo hacemos parte, sino que también contribuimos a forjar el carácter multicultural y artístico de esta ciudad. 
Bien es sabido que el arte, en todas sus manifestaciones, trasciende culturas e idiomas y enriquece a las sociedades. Nosotras hemos convergido en una sola, que es muchas a la vez: Berlín.

¡Ven a nuestro encuentro y déjate contagiar de FIEBER!”

Figura 8. Inauguración Fieber Festival, Galería Meinblau, Berlin, 2017.

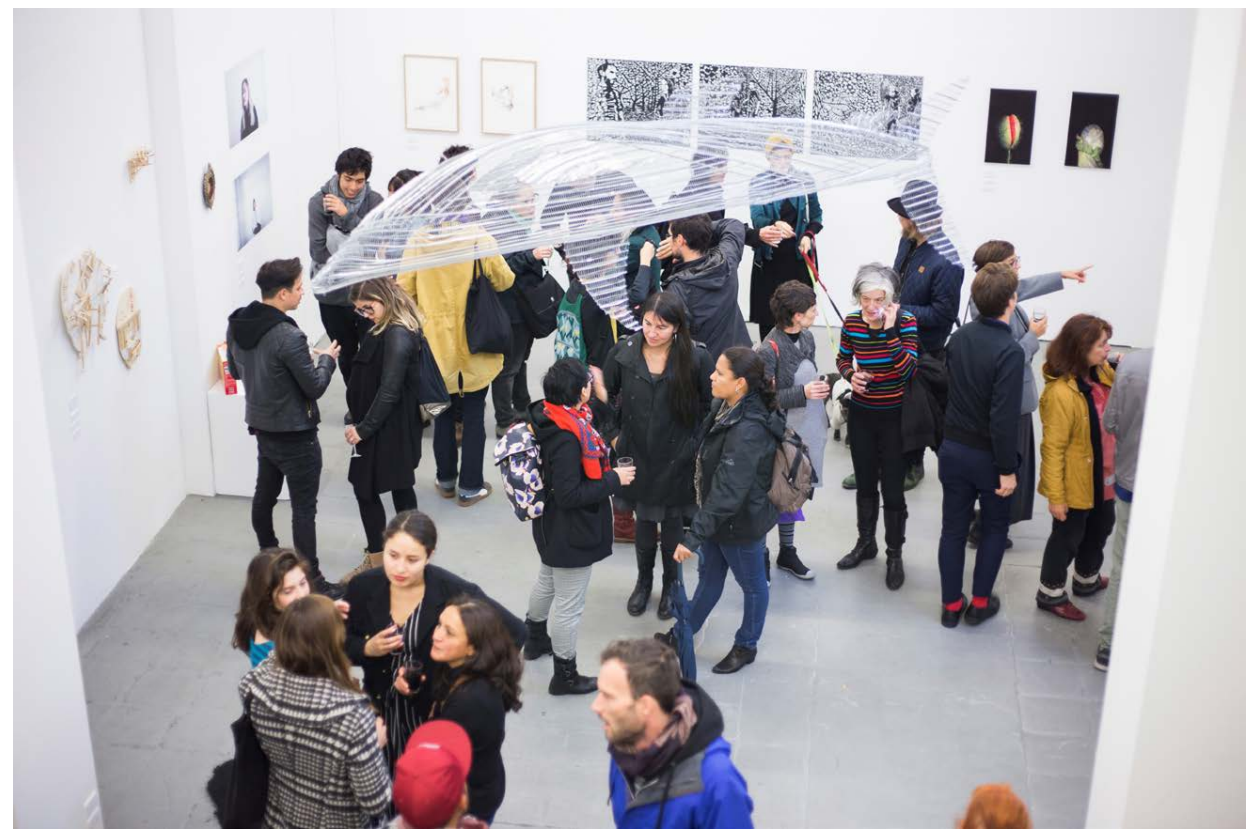

Fuente: Justina Leston

Era empoderador decir: ¡Aquí estamos, Berlín! Si bien no somos de acá y nos hemos reunido en nuestro grupo de mujeres iberoamericanas, formamos parte de esta ciudad, trabajamos y aportamos desde nuestras visiones, cultura y arte a la ciudad. Como una ofrenda, damos a la ciudad y a la ciudadanía lo mejor y más potente que tenemos, nuestras voces, nuestro arte, nuestra sensibilidad. Esta era una manera de permitirnos ser-estar, de unir fuerzas, de tomar espacios y de reconocernos, hacernos visibles entre nosotras, con nuestras miradas y hacia fuera para el resto de la sociedad.

En aquellas dos noches de finales de octubre del 2011 bailamos como loquitas, con risas cómplices de brujitas del siglo XXI, fue muy divertido. Creo que el festival removía muchas cosas en nosotras, especialmente para las que se involucraban en la organización. Una fuerza oculta nació en nosotras y tuvo que ver con la unión y el trabajo colaborativo de mujeres. Aquello fue como un hechizo y un conjuro que se repetiría cada dos años y hasta el 2017, para un total de cuatro ediciones. 
Figuras 9.1 y 9.2. Artista: Esedele, Empanadas esotéricas, Artista visual de Paraguay, 2020

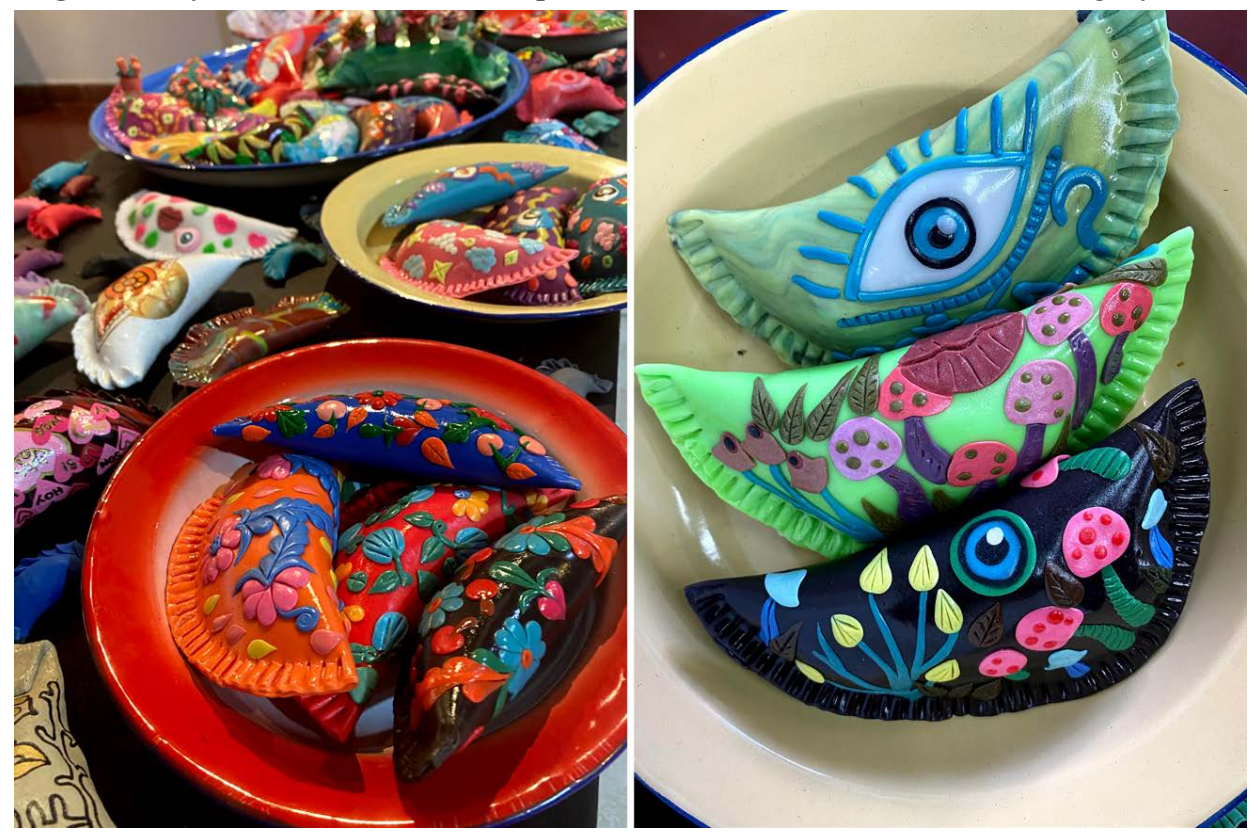

Fuente: Esedele

\section{Los encuentros sanan las pérdidas}

Sin embargo, el Festival nunca fue pensado como el inicio de una serie de festivales, al cabo de dos años y por insistencia de algunas de las chicas, convoqué a una reunión para conseguir equipo de trabajo para una segunda edición. En esa reunión apareció la chilena Bárbara Miranda con quien coordinamos los tres festivales siguientes, yo en la parte de coordinación más general y online y ella en la parte de producción de campo. Con el talento de Diana Toledo se realizó el diseño y la imagen de los tres primeros festivales. Lucía que había vuelto a Colombia, ayudó a la distancia con el segundo festival y otras chicas se fueron sumando en el camino, como Karina Villavicencio con sus ideas y reflexiones, Elsye Suquilanda con la música y difusión, Alexandra Bisbicus y Verónica Salguero, al pie de lucha para cualquier cosa, y con su casa abierta para reuniones, Irene Rojas Erlenbach con los videos y spots, mientras que Sophia Helena Gallbach y Valentina Utz se encargaron del montaje de la exposición en dos ocasiones. Xueh Magrini y Ligia Liberatori se centraron en discusiones, ideas, conceptos. Fueron muchas más las que aportaron y se unieron para darle forma al festival en las distintas ediciones ${ }^{7}$.

7 Ver equipo de trabajo y artistas por años en fieberfestival.com 
María Luisa Herrera Rapela

Testimonio: María Rapela, una artista costarricense en Berlín

Figura 10. Artista: Ana Correia, fotógrafa portuguesa, gelatina de impresión de plata

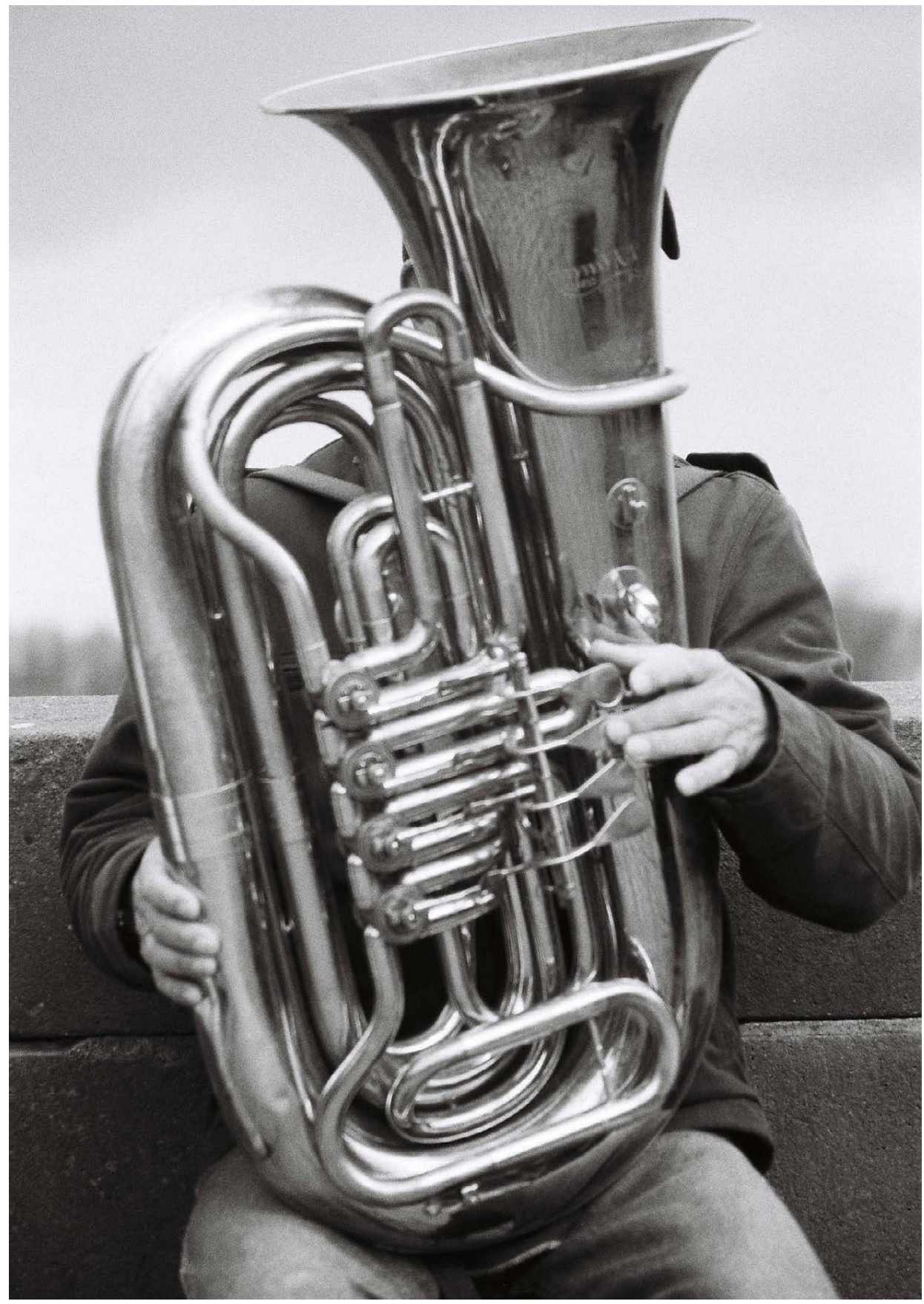

Fuente: Ana Correia 
Cambiamos de espacio en tres ocasiones, porque en una ciudad en constante transformación, los espacios culturales van desapareciendo o cambian de dueños, son comprados por empresas inmobiliarias que hacen que los precios de los alquileres sean cada vez más inaccesibles y que sin algún tipo de ayuda o apoyo a las artes se vuelven cada vez más inaccesibles. Intentamos sin resultados positivos conseguir fondos para poder financiar el proyecto, pero eso no impidió que continuáramos con el proyecto, incluso en una ocasión hicimos un crowdfunding $\mathrm{y}$ recogimos algunos fondos.

Figura 11. Artista: Valentina Utz, Chile.

Instalación en Galería Gabriela Mistral, Santiago, Chile. Taxonomía de los escombros.

Restos y escombros de viviendas sociales demolidas del barrio Puente Alto, 2019

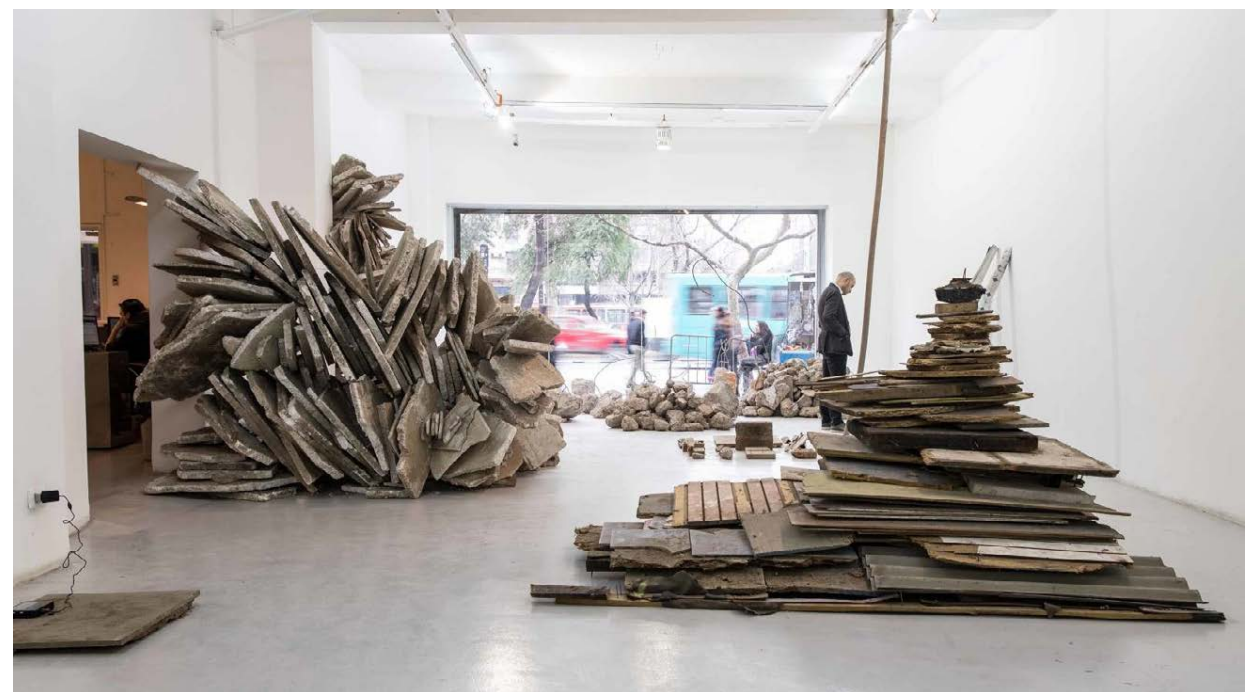

Fuente: Valentina Utz, fotografía: Francisca Razeto y Alexis Llerena

La primera edición la realizamos en una galería alternativa, Marzia Frozen, en Landsberger Allee 54, (una antigua fábrica de cerveza que luego fue vendida para construir apartamentos de lujo), su dueño, un colombiano que en paz descanse, nos la prestó por dos noches. Para la segunda edición, empezamos a buscar un lugar donde pudiéramos tener separada la galería del teatro y así ofrecer mejores condiciones para las artistas de las artes escénicas y de las artistas visuales.

La segunda y tercera edición las realizamos en el ACUD, una casa/centro cultural alternativo en el centro de Berlín, que nació después de la caída del Muro, cuando era muy común que se ocuparan edificios abandonados. Sin embargo, en ese lugar y en ese momento, todo era muy inseguro, no sabían si cerrarían o continuaría el proyecto porque les querían quitar el lugar y rematar la propiedad. Para cuando buscábamos un lugar para la cuarta edición habían rematado el proyecto 
y ya no era manejado por la misma gente, sino por gestores culturales con una visión diferente y ya no prestaban la galería para proyectos externos. De esa manera, tuvimos que buscar un lugar para la siguiente edición y no es tan fácil como parece, encontrar un lugar que tenga ambos espacios y que a su vez no se saliera de nuestras posibilidades económicas.

Logramos encontrar dos lugares separados, pero que se ubican en un mismo recinto, en el Pfefferberg, por un lado, el teatro/sala de eventos Haus 13 y, por otro, el espacio artístico Meinblau, una asociación de artistas que prestan su espacio a proyectos de interés por votación de los miembros. Esos dos lugares le dieron un alto nivel al festival, por las instalaciones, la técnica, la amplitud y la ubicación.

El Fieber empezó pequeño, pero desde el inicio era un éxito con el público, las inauguraciones y los teatros siempre estaban a reventar, así que el último lugar fue un cambio positivo y un paso adelante. Sin embargo, cuando empezamos a trabajar para la quinta edición, no conseguimos la galería y nos tuvimos que poner de nuevo a buscar un lugar. Luego las cosas se complicaron y no se pudo continuar.

\section{Reflexiones a raíz del festival y a través de lecturas varias}

Entendí que la unión hace la fuerza cuando hay metas y proyectos comunes, pero que por lo general las artistas también tienen su propia trayectoria y desarrollan sus obras de manera bastante individual e independiente de los proyectos por donde pasen. Esos espacios son como cruces de camino, en un lugar y un momento dado, donde personas que recorren caminos diversos y variados se encuentran y se retroalimentan.

Creo que las artes en general son un espacio de intervención social que convoca a las artistas, así como al resto de la sociedad a pensar, a reflexionar y a expresarse de manera auténtica. Las personas artistas necesitan del diálogo e intercambio entre ellas, pero también con el público. Sino se expone, sino se muestra, sino se abre el telón o se conecta un micrófono a los parlantes para que una poeta lea sus textos, quedan cosas por decir, no circula esa energía que las artistas hacen que se mueva a través de sus obras y trabajos. 
María Luisa Herrera Rapela

Testimonio: María Rapela, una artista costarricense en Berlín

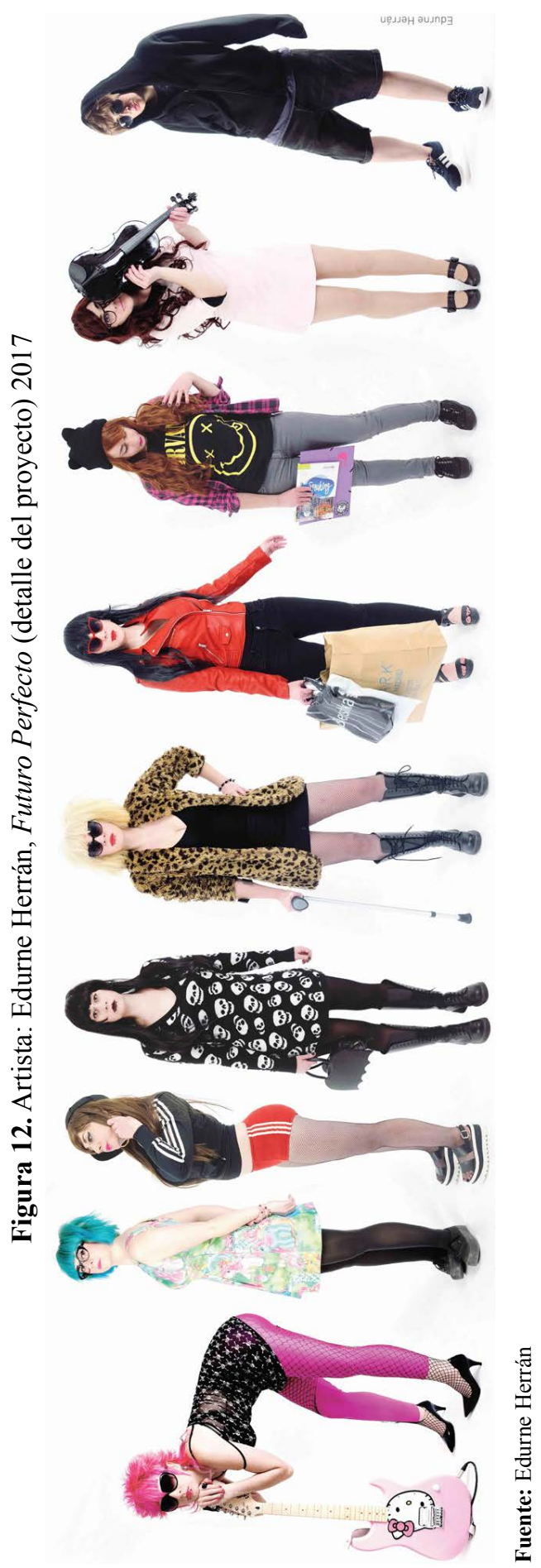

ISSN 1023-0890

EISSN 2215-471X

Número 28 • Julio-Diciembre 2021 
El surgimiento del Fieber convocaba a mujeres artistas Iberoamericanas en Berlín, que estaban viviendo procesos parecidos, con ciertas similitudes para participar, colaborar o mostrar su trabajo. El contexto migratorio, las dificultades que existen de integración debido al idioma, la necesidad de avanzar en el propio arte, fueron probablemente factores que hicieron que el festival cubriera una necesidad, una carencia. Durante el festival surgían afinidades entre las artistas, se creaban redes de apoyo o de colaboración, también surgieron proyectos nuevos. Tener una red de apoyo y contención en las variadas disciplinas facilita de alguna manera la integración de las personas en una ciudad nueva.

Las personas en contexto migratorio llevan consigo "una valija" de recursos, ideas, conocimientos y talentos que desean poder usar para desarrollarse en el lugar de acogida, pero que no siempre logran poner en práctica desde un inicio. Nosotras poníamos en la mesa una serie de tareas necesarias a realizar y las artistas participantes decidían si se involucraban o no. Viendo el interés de las artistas en colaborar e involucrarse en un fin común, pude comprobar que las personas en contexto de migración se pueden llegar a sentir "realizadas" y "valorizadas" cuando pueden "crear o aportar algo" y mostrar su arte junto a otras personas que viven experiencias parecidas. Este sentimiento de valorización es particularmente importante en este contexto migratorio, donde la adaptación es muy difícil, toma mucho tiempo y se puede generar una baja autoestima por la lentitud del proceso en integrarse a nivel social o laboral.

La gestión social participativa con mujeres, puede ayudar a fortalecer lazos y crear la sensación de pertenencia a un proyecto, mejorar la autoestima y el valor propio a través del trabajo colaborativo con las otras participantes. El trabajo colaborativo e interdisciplinario permite a las participantes experimentar el conocimiento que surge como fruto del trabajo colectivo y descubrir la fuerza y la creatividad que hay en cada persona. Hay un proceso interesante que se da en ese ver y reconocer a otras personas y que estas te vean y reconozcan. Nosotras lo llamábamos Fiebre, que es en realidad lo que significa Fieber: fiebre, emociones fuertes, amor, adrenalina, colaboración, subida de temperatura, oxitocinas, subidón de alegría, energía. 
Figura 13. Cartel 3era edición Fieber Festival

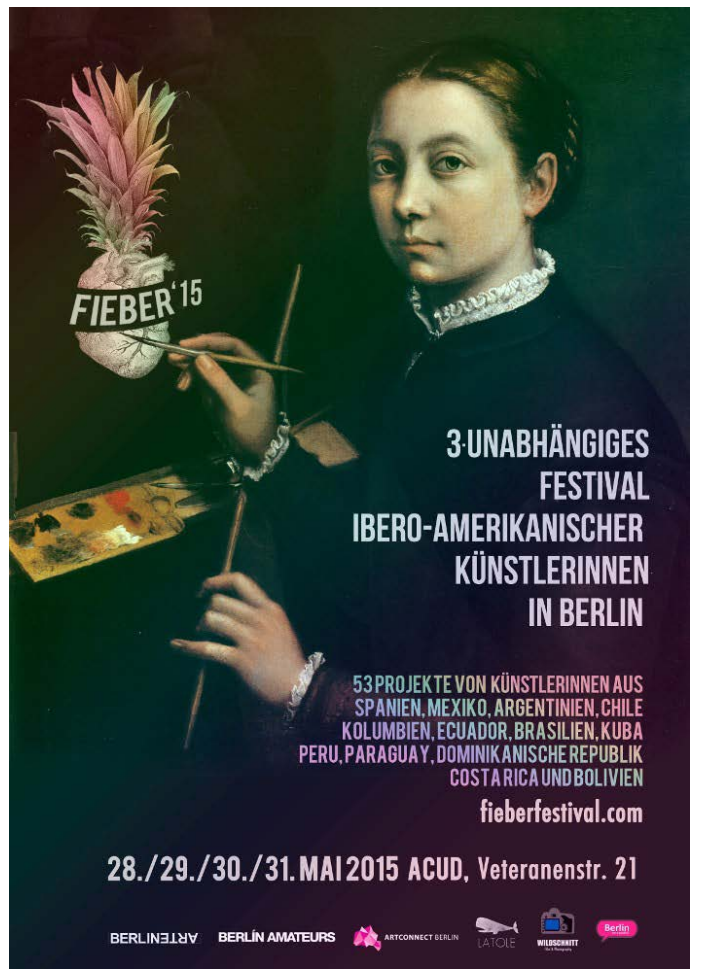

Fuente: Fieber Festival 2015, diseño: Diana Toledo (Latole)

\section{Sobre las Mujeres en el Arte}

Cuando estábamos en la fase de promoción y nos hacían entrevistas, siempre nos preguntaban porque hacíamos un festival "solo de mujeres". Eso nos llevó a reflexionar, investigar, sobre un tema del que ni siquiera nosotras mismas estábamos del todo conscientes y es el hecho de que las mujeres artistas han sido invisibilizadas y olvidadas en la historia del arte, como lo describe en su libro Ángeles Caso, Las Olvidadas. Una Historia De Mujeres Creadoras (2005).

En la novela El mundo deslumbrante (2014) de la estadounidense Siri Husvetd, el personaje principal de la historia es una mujer artista con años de trayectoria y con poco reconocimiento en la escena del arte en New York, la cual hacía varios experimentos para comprobar si había una relación entre el hecho de que ella fuera mujer y el éxito y aceptación de su obra. Para eso consiguió a varios personajes masculinos que se harían pasar por los autores de su obra y así experimentar si su arte tenía más aceptación y éxito cuando era producido por un hombre.

¿Tienen entonces los hombres mayor éxito en el mundo del arte por el simple hecho de ser hombres?, ¿O es el sistema del arte el que favorece a los artistas hombres? como ya lo denunciaban las Guerrilla Girls en New York en la década de los 80's, en un cartel que decía: ¿Tienen que estar desnudas las mujeres para poder entrar al MET (Metropolitan Museum of Art)? Menos del 5\% de los artistas que están en las salas de arte moderno son mujeres, pero $85 \%$ de los desnudos son de mujeres. Con el paso de los años, las cifras no han cambiado mucho las cosas $^{8}$. La Asociación de Mujeres en las Artes Visuales (MAV) de España, dice, por

8 guerrillagirls.com Grupo de artistas anónimas que desde 1985 denuncian la desigualdad que existe en el mundo del arte y la poco representatividad de mujeres artistas en museos y galerías en la ciudad de New York. Con máscaras de gorilas denuncian a través de carteles y otros medios de guerrilla urbana las desigualdades en el sistema del arte y su predilección por los artistas hombres. 
ejemplo, que es necesario generar políticas de igualdad y mayor acceso a mujeres en los diferentes espacios de las artes visuales (Informes variados de MAV) ${ }^{9}$.

Figura 14. Artista: Alexandra Bisbicus, artista colombiana. Nacimiento, arte textil, 2020

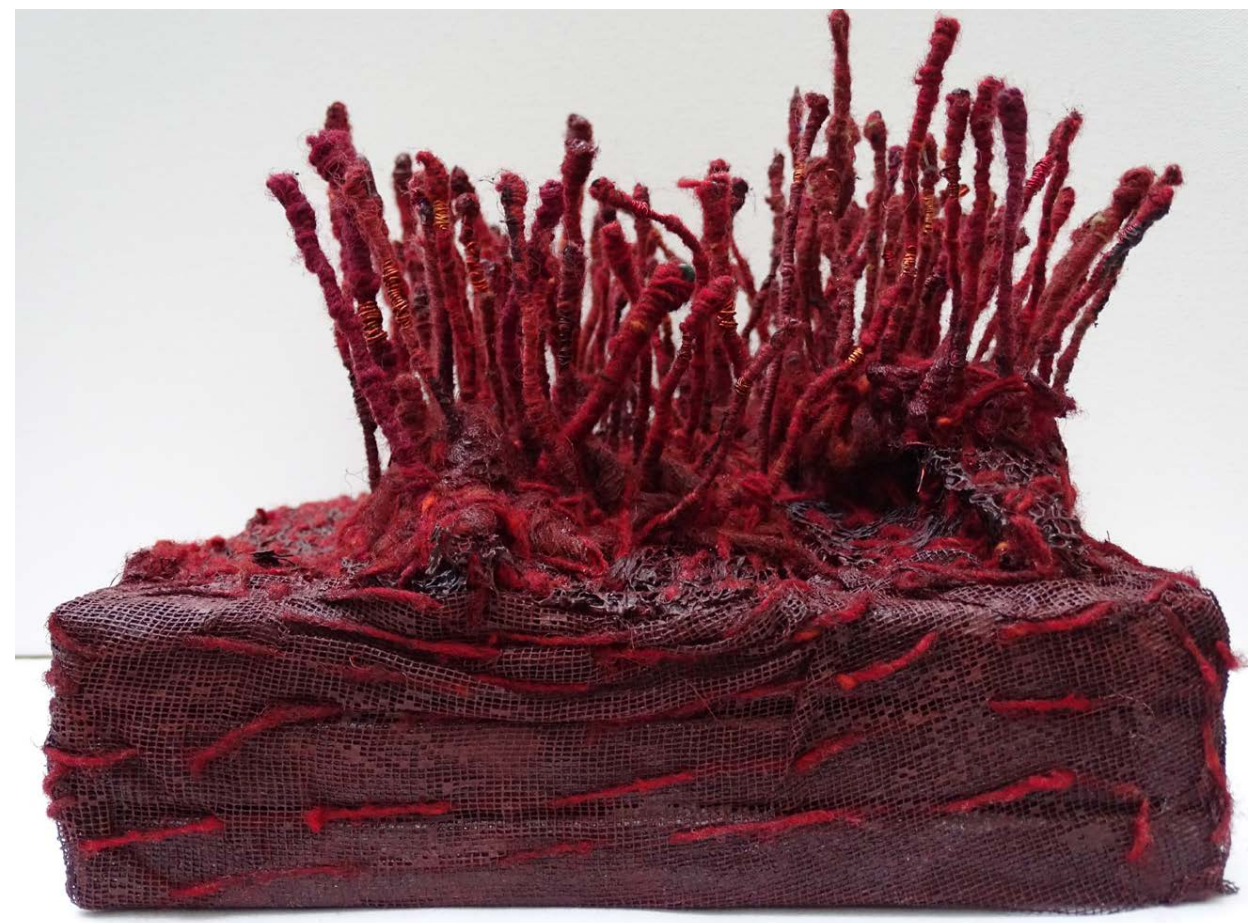

Fuente: Aymara v. Borries

Quizás es simplemente un problema estructural y eso hace que sea mucho más difícil para las mujeres llegar a ciertos espacios y por eso me parece valiosa la reflexión de Karina Villavicencio:

El sentimiento de estar en la periferia y de no poder llegar al centro era cada vez más fuerte y es ahí cuando tomé consciencia de que la única solución para mí era la de dejar de repetir discursos sociales aprendidos y comenzar a contar mi propia historia, es decir, ponerme a mí misma en el centro de mi discurso. No se trata de una búsqueda individualista, sino de darse la posibilidad de hablar en primera persona, sin tener que citar a sujetos que a menudo son hombres, blancos y que están en espacios de poder, decidiendo lo que está bien o no, lo que está adentro o lo que se queda afuera ${ }^{10}$.

9 MAV, Asociación de Mujeres en las Artes Visuales de España https://mav.org.es (Consultado, 25-01-2021)

10 María Luisa Herrera Rapela "Entrevista a Karina Villavicencio una artista que utiliza el cuerpo como superficie para la reflexión artística" Blog: María Rapela Una tica en Berlin, 2021, https://unaticaenberlin. blogspot.com/2021/01/karina-villavicencio-una-artista-que.html (consultada en: 25-01-2021) 
En las discusiones para la organización de la edición 2017 tuvimos que reformular lo que entendíamos por "mujeres", y siguiendo los usos de otras asociaciones pusimos en la convocatoria, que:

Por mujeres entendemos todas las personas que se reconozcan como tales incluyendo todas las diversidades sexuales, de género, de identidades, etc. Lo cual quizás abrió el llamado a un público más amplio y a personas que quizás están entre géneros y no se sienten representadas por ninguno de los dos polos heterosexuales.

También se nos ha cuestionado el hecho de que el festival fuera de artistas iberoamericanas y de que convocáramos apelando a las nacionalidades o a conceptos colonialistas como Iberoamérica, en vez de convocar bajo criterios de otro tipo, como podrían ser temáticos o conceptuales. Pero lo cierto es que, como expliqué antes, el idioma es un factor que nos unía en la mayoría de los casos, aunque las portuguesas y brasileñas no necesariamente se podrían haber sentido atraídas por un llamado en castellano, cosa que también intentamos modificar y tener algunos textos en portugués, traducidos por las mismas artistas de esos países. A su vez, tuvimos colaboración constante de chicas alemanas como Ulrike Geier y otras que nos ayudaron a traducir y corregir todos los textos al alemán, tanto para la página web, flyer, cartel, prensa, social media, entre otros.

En los dos primeros festivales no utilizamos ningún tema en particular para la convocatoria. Pero ya para la tercera y cuarta edición, nos reunimos para hacer una lluvia de ideas, conversar sobre posibles temas y darle una unidad de reflexión que aglutinara de alguna manera las obras, más allá del hecho de que fuéramos iberoamericanas en Berlín. Para la tercera edición el tema estaba resumido en una piña con corazón, la cual de alguna manera, es una representación visual de todo lo que estábamos dando con nuestro trabajo a la ciudad y a nosotras. En la cuarta y última edición el tema era "Identidades en cambio" y dejaba las puertas abiertas para que cada una reflexionara y expusiera su trabajo bajo una temática común. 
Figura 15. Artista performance Kysy Fischer, Fieber Festival, Meinblau, Berlin 2017.

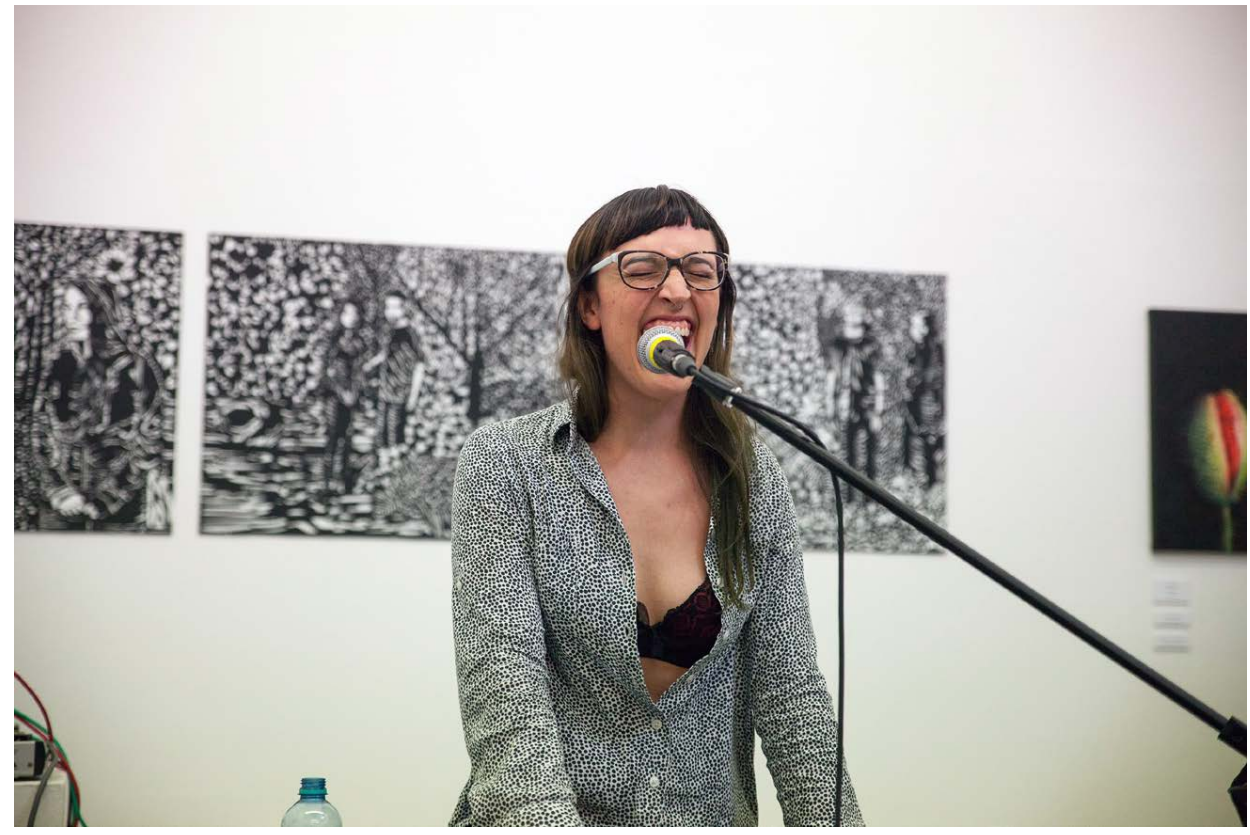

Fuente: Fieber Festival 2017, fotografía: Daniela Carvajal

\section{Mujeres y dinero: El valor del trabajo invisible}

Leyendo a Silvia Federici sobre la invisibilización del trabajo de las mujeres en diversos ámbitos de la sociedad y de la economía, me hizo pensar de que hay una zona oscura, nublada, en la que quedan las actividades no remuneradas que se realizan en la sociedad y en nuestras vidas cotidianas ${ }^{11}$ ¿Qué rol juega el trabajo remunerado y el no remunerado en esta sociedad capitalista?

Cuando reflexionábamos sobre la sostenibilidad del proyecto nos hemos dado cuenta de los importantes recursos que movilizábamos las organizadoras y las artistas al hacer un festival como estos sin ningún tipo de remuneración, ni salarios.

Sin embargo, a veces, no sé si especialmente las mujeres artistas y más si somos de artes plásticas, tenemos un pequeño gran problema en la asociación entre arte y dinero. Las de música, en cambio, lo tenían más claro y eso nos llevó a tener algunas discusiones donde tomamos consciencia de que el trabajo que cada artista aportaba al festival eran recursos humanos, tiempo, energías y conocimientos, que si hubiésemos tenido que pagar podríamos haber hablado de un presupuesto de 100.000 euros o más en cada edición. Gracias al trabajo no remunerado y

11 Silvia Federici, Revolución en punto cero. Trabajo doméstico, reproducción y luchas feministas (España, Editorial Traficantes de Sueños,10 junio 2013). 
hecho con cariño de muchas artistas, traductoras, diseñadoras, fotógrafas y colaboradoras varias, se logró hacer un festival con presupuestos mínimos, para cubrir gastos básicos como alquileres, técnicos e impresiones. El hecho de que las artistas o las organizadoras no hayan sido remuneradas y de que todo el trabajo fuera un trabajo "voluntario" significaba que cada persona debía asegurarse los ingresos en otras áreas para poder dar y ofrecer ese trabajo de gratis.

En nuestra actividad de "índole voluntario y solidario", en nuestro afán de visibilizar el arte de muchas artistas, estábamos reproduciendo lo que sucede en muchas otras esferas de la sociedad, así como en la historia: el de la gratuidad del trabajo de muchas personas para un fin común. Hay muchos trabajos que son remunerados, y hay trabajos poco valorados pero necesarios, que muchas personas realizan en nuestras sociedades, en especial los de muchísimas mujeres a lo largo de la historia, no solo en el arte, sino en el ámbito doméstico y en otras esferas de la vida pública y privada.

No es cuestión de idealizar el trabajo asalariado, ni de desacreditar el trabajo voluntario o no remunerado, pero al vivir en una sociedad capitalista, donde sobreviven primordialmente los modelos empresariales que generan ganancias económicas, reciben apoyos estatales o de otra índole, muchos proyectos pueden resistir durante un tiempo, pero siguiendo esta lógica la mayoría están destinados a desaparecer.

El trabajo voluntario con fines comunitarios o artísticos es digno y maravilloso para quienes lo realizan, ya que implica hacer algo por amor, interés, aprendizaje, socialización, construcción de redes, acercarse a las cosas y a las personas sin el dinero como intermediario. Pero para que este trabajo voluntario se pueda hacer, es porque existe una base económica que ya está resuelta, por lo que el trabajo voluntario se realiza desde el poco tiempo libre que ha quedado, después de invertir horas en un trabajo con remuneración económica. 
Figura 16. La poeta Elsye Suquilanda y el Kollektiv Dunckerstr, Fieber Festival, Teatro Acud, Berlín, 2015

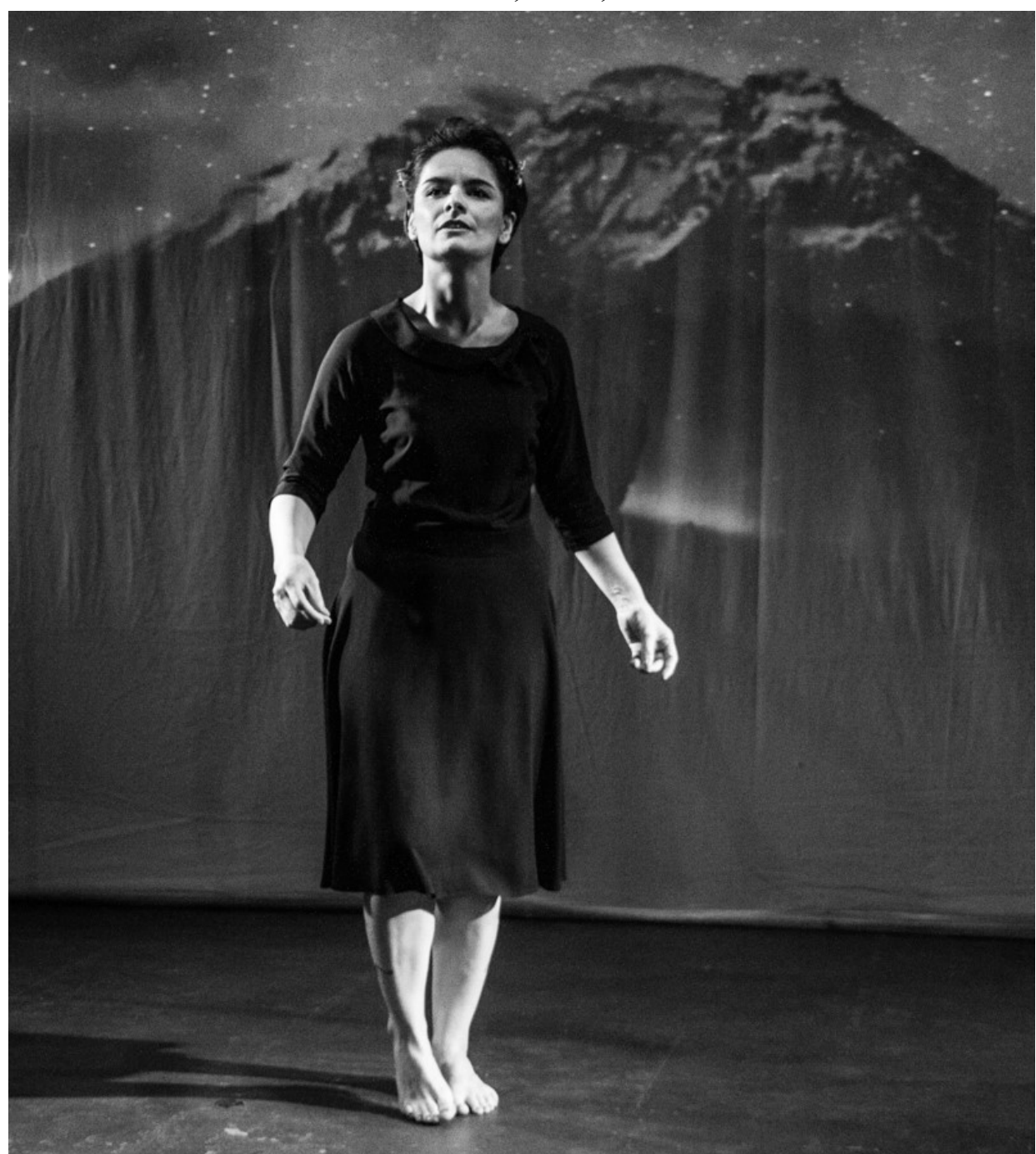

Fuente: Fieber Festival 2015, fotografía: Camila Berrio

El festival convocaba a artistas profesionales en Berlín, por lo tanto, partíamos de la idea de que el arte no es un hobby, sino una profesión. Lo cierto es que para una mayoría el vivir del arte no es siempre algo evidente ni fácil de lograr. Creo que también nos faltó -o me faltó- la visión y el convencimiento de tomarnos las cosas más en serio y de pensar en cómo hacer un festival sostenible y verlo como un proyecto de vida que se convirtiera en el principal pilar económico, pero quizás simplemente hicimos lo que pudimos en un momento dado. 


\section{Reflexiones y algunas artistas que participaron}

¿Cómo seleccionábamos a las artistas? Partíamos de la base de que tenían que ser artistas de Iberoamérica asentadas en Berlín y creadoras en alguna disciplina artística. Los criterios de selección eran formación, profesionalidad demostrada -página web, currículum, fotografía, textos, posicionamiento-, entre otros, pero no éramos tan estrictas tampoco. Intentábamos que no se quedaran artistas por fuera, pero cuando había mucha demanda en un área -como en artes plásticas-, partíamos seleccionando a quienes se presentaban de manera más profesional, quienes contaban con recorrido y actividad regular, o quienes contaban con una formación en su área, o por el trabajo en sí, es decir, si tenía coherencia con la temática.

En los primeros festivales las coordinadoras seleccionábamos a las que entraban y las que no, pero en el último festival, invitamos a varias chicas de cada área para tomar una decisión fundada en el criterio de varias personas y por especialidades. La idea no era crear un espacio excluyente, por lo contrario, sino que fuera lo más inclusivo posible.

Coordinar el festival hizo que conociera el trabajo de muchísimas artistas y me abriera a un mundo de nuevas sensibilidades para comprender como las artistas se posicionan desde distintas disciplinas, perspectivas y visiones. Algunas propuestas eran innovadoras y otras menos, pero todas tenían y merecían un lugar en el festival. Era interesante ver el tipo de arte según el país o disciplina, por ejemplo, las propuestas más provocadoras e impactantes que vi fueron en el ámbito del performance, de las artistas brasileñas Kysy Fischer, Kupa Lua, Maicira Leão, Daiane Rafaela o el trabajo performativo de la argentina Karina Villavicencio y de la paraguaya Esedele.

También noté un alto nivel de las artistas chilenas y podría citar a Muriel Gallardo, Rosario Aninat, Valentina Utz, Katica Puga con búsquedas particulares en materiales y formas.

En artes plásticas, pasaron artistas como Xueh Magrini con sus dibujos y live paintings, el arte textil de Alexandra Bisbicus, los dibujos en gran formato de Verónica Salguero, la pintura realista de Duna Ronaldo, la mexicanidad de Rosaana Velasco, los trazos carnosos de Marina Roca Die o los collages de Rebeka Elizegi. 
Figura 17. Taller: Arte, Historia y Mujeres por Karina Villavicencio, Fieber Festival, Acud, Berlín, 2015

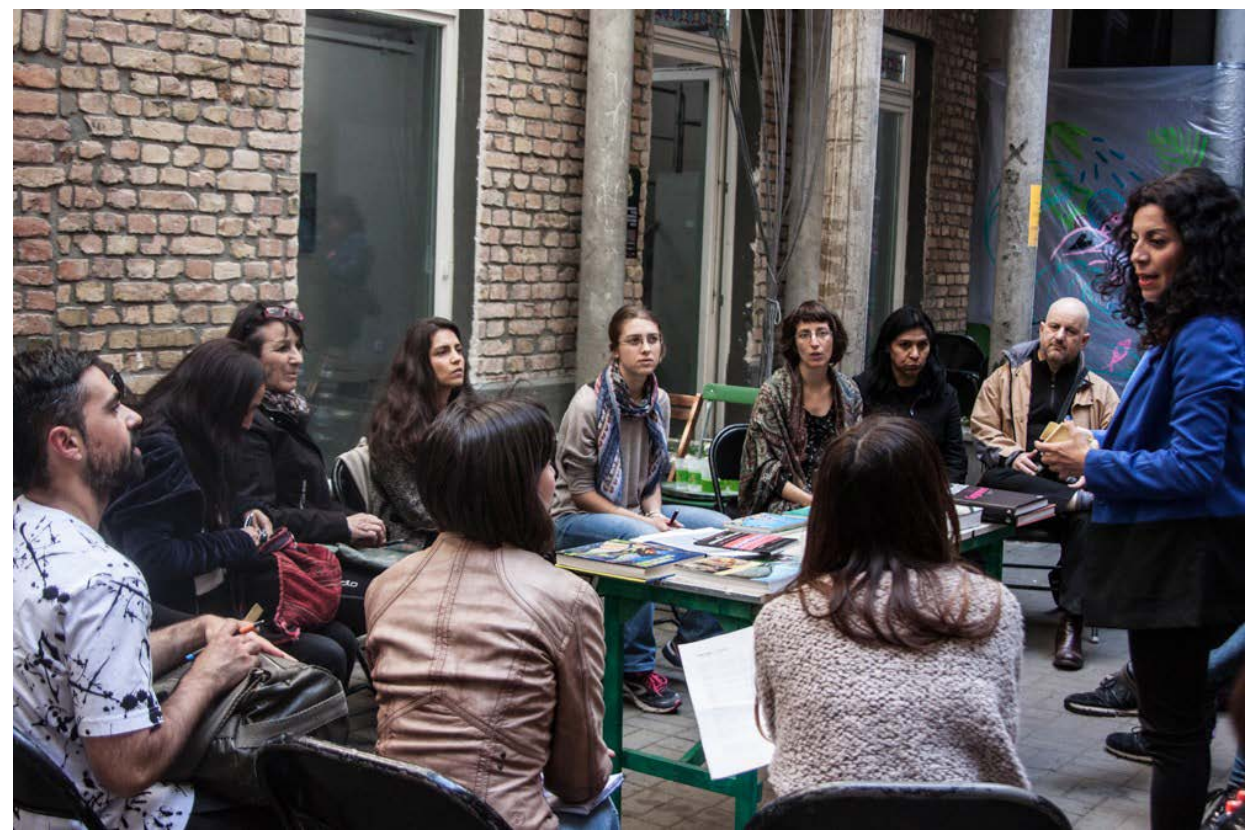

Fuente: Fieber Festival 2015, fotografía: Camila Berrio

Hubo siempre mucha presencia de fotógrafas, ahí destacaría a la española Diana Toledo, a la portuguesa Ana Correia con su fotografía street, en analógico blanco y negro, o las búsquedas visuales de la chilena Tiaré Maldonado, la fotografía antropológica de la mexicana Anahís Sanchez Terán, la investigación de cuerpos y movimiento de la española Ainoha Valle, o los foto-collages y textos de Florencia Lizama. Dentro del arte conceptual, las españolas Edurne Herrán, María Alcaide, María León y María Amparo Gomar Vidal se constituyeron en muy buenas representantes.

En el campo de la literatura hay algunas escritoras creando y escribiendo en castellano en Berlín, de las cuales podría citar a Esther Andradi con sus micro-relatos, en poesía a Marta Gantier, Sonia Solarte, Claudia Sierich, María Nancy Sanchez Perez, Ramona de Jesús o Elsye Suquilanda con su poesía acompañada de música y performance, y en novela a Bibiana Candia, Mara Mahía, entre otras.

En música pudimos escuchar la voz y textos de la argentina Catnapp, de Imperio o los paisajes sonoros y experimentales de la brasileña Dibuk, M.i.p.V (Músicas intermináveis para Viagem) de Laura Leiner, las composiciones de Julieta Brur, Minsk, Marta Tai y las técnicas de voz extendida de Ligia Liberatori, entre otras. 
En cuanto a la danza/performance, resaltaron los trabajos de Sara Lu, Laura Pacheco, Sabina Velasco, Melisa Palacio López o la dominicana Tatiana Mejía, entre otras, mientras que en teatro pudimos ver el trabajo humorístico de Paloma Lirola, el trabajo dramático de Lorena Valdenegro o las interpretaciones de monólogos por Adriana Jacome y la colombiana Jeiny Cortés.

También en video-arte sobresale el trabajo de la vasca Blanca Ortiga, la costarricense Diana Barquero, la peruana Irene Rojas Erlenbach, la artista visual y VJ Ana Nieve Moya, y los experimentos visuales de la argentina Carolina Boettner.

En general, animábamos a las participantes para que participaran, colaboraran, hicieran o probaran cosas nuevas. En una edición surgieron dos proyectos work in progress entre varias artistas, también las animábamos a dar un taller o una charla y así generar un debate sobre el tema Mujeres y Arte, como sucedió con la primera mesa redonda dirigida por Karina Villavicencio en el 2015. Al ver el éxito de la propuesta, quisimos incluir estos temas en las siguientes ediciones, así sucedió en el 2017 con el Taller-Laboratorio Interdisciplinar Mujeres Arte-Memoria, Subjetividad y Archivo a cargo de Karina Villavicencio y Thais Vera Utrilla, así como con una conferencia de Blanca Ortiga, artista, teórica y educadora en esta área. También, hubo un taller de teatro para la niñez a cargo de Lorana Valdenegro y un taller de arte-terapia a cargo de Alexandra Bisbicus, así como una presentación magistral de la obra Futuro Perfecto de la artista Edurne Herrán.

Estas experiencias de animarse a hacer cosas en un terreno seguro donde no se te juzga, pueden marcar un antes y un después en las personas, porque podés probar cosas nuevas en áreas que te interesan, o formatos que quizás no has probado antes y definan posibles rutas en un futuro.

El haber trabajado de voluntaria tomando fotos y en el blog de un festival de cine en varias ocasiones me había dejado que había que fotografiarlo todo, y si es posible, crear un blog escrito o poder filmar la actividad. Por ello, también animé a las chicas a hacer entrevistas, a preguntarse entre ellas y que esto también sirviera como contenido para redes sociales. En la edición de 2015, y particularmente en la edición de 2017, las entrevistas y fotografías funcionaron bastante bien, gracias al trabajo de las fotógrafas Daniela Carvajal y Justina Leston.

En los primeros años yo hacía el registro fotográfico o mi compañero y otras artistas participantes, por lo que siempre tuvimos diversidad de fotos y miradas, pero en el 2015 y el 2017 tuvimos a excelentes fotógrafas que se dedicaron exclusivamente a registrar el festival, en el 2015 fue Camila Berrio y en el 2017 Daniela Carvajal y Justina Leston. Igualmente, en el 2017 logramos que un patrocinador externo -Among Suspect Project- filmara y editara un video con algunas impresiones del festival. 


\section{El Fieber Festival en el contexto iberoamericano en Berlín}

En Berlín alrededor de un 35\% de la población tiene orígenes extranjeros o un pasado y origen migratorio ${ }^{12}$. De 3.77 millones de personas en Berlín en el 2019, 2.45 millones son alemanes sin orígenes migratorios, 1.32 millones tienen origen migratorio. De estos últimos 543.000 tienen un pasaporte alemán y 777.000 son extranjeros ${ }^{13}$.

La comunidad hispanohablante es pequeña y está muy por debajo de la población de la comunidad turca (182.000), polaca (114.000), países árabes (154.000) o de países de la ex-Unión Soviética (145.000), que se encuentran entre los más representados. La comunidad hispanohablante se hace sentir en la vida de la capital, ya sea desde la empresa privada con restaurantes, librerías o eventos (musicales, conciertos, noches de baile), o desde pequeños centros culturales, así como con asociaciones, embajadas, instituciones, iniciativas variadas, festivales, entre otros.

La movida hispanohablante se compone de gente originaria de los países hispanohablantes de primera o segunda generación de Latinoamérica, España y Estados Unidos asentadas en Berlín. Cuando se habla de Iberoamérica, en cambio, se incluye a Brasil y Portugal y se excluye a Estados Unidos.

En Alemania, y en Berlín en particular, en algunas escuelas primarias ${ }^{14}$, secundarias y universidades se reciben clases de castellano como segunda o tercera lengua, asimismo, se hacen intercambios estudiantiles en regiones donde se habla dicho idioma. También, el sistema educativo alemán tiene 140 Instituciones educativas fuera de Alemania, 33 de estos centros están en Latinoamérica y 6 en España (DAS) ${ }^{15}$.

Según el documento oficial del gobierno alemán ${ }^{16}$ :

Las relaciones de Alemania con América Latina y el Caribe ocupan un lugar destacado en el seno de la comunidad internacional. Los valores comunes e intereses convergentes, así como la estrecha vinculación cultural de raíces

12 bamf.de Ministerio de Extranjería y Migración. Según la definición oficial: Migrationshintergrund significa origen migratorio: "Una persona tiene un origen migratorio si él o al menos uno de sus padres no ha nacido con la ciudadanía alemana". En concreto, la definición incluye lo siguiente: 1. Extranjeros inmigrantes y no inmigrantes; 2. Inmigrantes y no inmigrantes naturalizados; 3. (Spät-)Aussiedler (alemanes retornados de ex-países de la Unión Sovietica después de varias generaciones); 4. Los descendientes de los tres grupos antes mencionados nacidos con ciudadanía alemana. Traducción libre mía.

13 Tagespiegel, periódico local, fecha: 27-02-2020, https://www.tagesspiegel.de/berlin/neue-zahlen-zu-bevoelkerungin-berlin-35-prozent-der-berliner-haben-migrationshintergrund/25589402.html (consultado 25-01-2021)

14 berlin.de - El portal oficial de Berlín dice que hay 5 escuelas/colegios que ofrecen la enseñanza del castellano como segunda lengua o que son bilingües. https:/www.berlin.de/kultur-und-tickets/tipps/multikulti/ spanisches-berlin/2279720-3039790-spanischsprachige-schulen.html (consultado 25-01-2021)

15 DAS, Deutsche Auslandsschulen, https://www.auslandsschulwesen.de/Webs/ZfA/DE/Schulnetz/DAS/Weltkarte/weltkarte_node.html (consultado 25-01-2021)

16 Ministerio de Relaciones Exteriores de Alemania, 2010. "Alemania,América Latina y el Caribe: Lineamientos del Gobierno Federal”. https:/www.auswaertiges-amt.de/blob/1496412/14f0ce6227e6613684b599f9016f8c99/lak-konzept-span-data.pdf (consultado 02-06-2021) 
históricas, crean una base única sobre la que desarrollar la cooperación, tanto bilateral, en beneficio mutuo, como multilateral, en tanto que responsabilidad compartida.

Esto hace que en Latinoamérica haya muchas personas jóvenes que crecen con un pie en un país latinoamericano y con la mirada puesta en Alemania y viceversa.

En cuanto al turismo, tanto España como los países latinoamericanos, son un destino muy atractivo para los alemanes, lo cual hace que en general la cultura y la lengua sean vistos con cierto atractivo y fascinación. Según datos de lateinamerika.org en el 2019 la cifra de turistas alemanes en Costa Rica fue de 80.580, en Chile de 82.541, en Colombia de 78.856 y en Perú de 65.318, entre los principales destinos turísticos (lateinamerika.org) ${ }^{17}$.

\section{Asociaciones y comunidades hispanohablantes}

En Berlín hay una variedad de asociaciones culturales y de ayuda a las personas migrantes. Algunas de las más importantes son las asociaciones de mujeres como Xochicuicuatl e.V y Mamis en Movimiento e.V, la Casa Latinoamericana en Berlín, la Oficina Precaria o La Red, entre otras. Mucho del trabajo que realizan es voluntario, pero gracias a las cuotas y donaciones que reciben, ellas ofrecen actividades culturales, de entretenimiento, talleres variados; además de ayuda y apoyo en temas migratorios, familiares, de integración, multiculturalidad o de celebración de fechas importantes.

También hay asociaciones por nacionalidades o temas políticos, como por ejemplo la Asociación Centro Argentino en Alemania (Caarne), o la asociación Violeta Parra, que reúne a una parte de la comunidad chilena, entre otras. La asociación La Calaca e.V., por ejemplo, celebra con grandes festejos y colorido el día de los muertos según la tradición mexicana. Estas y otras asociaciones hacen encuentros y comidas, presentan a sus artistas en los eventos y ayudan a sus compatriotas en temas migratorios, entre otros.

\section{Instituciones relacionadas con Iberoamérica}

Los países más grandes y fuertes e influyentes de Latinoamérica tienen no solo embajadas más grandes, sino que además ofrecen un calendario cultural de actividades más variado. Como ejemplo está la embajada de México, la de Argentina o la de España, con personal dedicado a la gestión cultural y a la promoción de sus artistas.

17 lateinamerika.org - Datos de turismo alemán en Latinoamérica, 2020. https://www.lateinamerika.org/images/pdf/Tourismusentwicklung_2019_DE.pdf (consultado 25-01-2021) 
El Instituto Cervantes, es un importante actor en la capital a nivel de idioma, ya que cuenta con un edificio céntrico donde se ubica la escuela de enseñanza del castellano, una biblioteca-mediateca y se realizan eventos culturales.

Otra institución que hace de Berlín un foco de diálogo académico permanente con Latinoamérica es el Instituto Iberoamericano, el cual tiene uno de los más grandes y completos archivos relacionados con Iberoamérica. En sus instalaciones se organizan también eventos culturales y académicos.

Por otra parte, el Instituto Latinoamericano (LAI) de la Universidad Libre de Berlín cuenta con una carrera y un máster especializado en Estudios Latinoamericanos en Ciencias Sociales y Antropología, lo cual fomenta los estudiantes alemanes interesados en la región, sus idiomas y sus culturas, así como estudiantes de Latinoamérica que vienen a especializarse.

\section{Festivales, iniciativas y colectivos hispanohablantes en Berlín}

En cuanto a iniciativas, hay muchas y cambian con el paso del tiempo, algunas ya han desaparecido, otras están activas y están las que aún no existen, pero algún día nacerán.

En el ámbito de la literatura hay talleres de lectura, literatura, escritura, organizados por escritoras independientes, como por ejemplo Samanta Schweblin o Esther Andradi dentro de librerías (como Bartleby, Andebuch, La Escalera) o en espacios culturales o asociaciones. De igual forma, hay eventos de lectura y presentaciones de poesía, música, open mics en bares, librerías y cafés. El Festival Latinale de Poesía Latinoamericana está consolidado e invita cada año a personas poetas seleccionadas de Latinoamérica a venir a Berlín y leer sus trabajos junto a demás poetas del ámbito local latinoamericano residentes en Alemania ${ }^{18}$.

Hay festivales y muestras de cine, enfocados en determinados países (Colombia, Argentina, España), o a nivel regional se puede mencionar Lakino, un festival de cine latinoamericano. En el mundo del teatro hay personas y grupos que también organizan talleres abiertos para adultos o para la niñez. Cada tanto presentan su trabajo en noches de teatro, de comedia o de improvisión. Algunos grupos actuales son: Berlín Es Impro, La chancla Migrante, Aquí Theater Berlin e Iberoamerika Ensamble, entre otros.

En Berlín hay muchas exposiciones en artes visuales, galerías y centros de arte. Algunos tienen una delimitación internacional, por países, regiones o por temas, esto varía según el comité curatorial y el financiamiento. Ha habido algunas iniciativas que se organizan por países como una exposición de artistas

18 Latinale, http://latinale.blogsport.eu (consultado 02-06-2021) 
españoles en Bethanien Haus con apoyo de la embajada española o Chilean Conexion, una iniciativa independiente de artistas de Chile en Berlín que lleva alrededor de tres ediciones.

Hay algunos espacios y galerías que ofrecen residencias artísticas y son dirigidas por personas artistas o curadoras hispanohablantes como Glogauer, Somos Berlin o, el más reciente, Flusslab organizado por la argentina Carolina Boettner. Desde hace unos años Karne Kunst, ha generado bastante movimiento y espacios para artistas visuales, así como la organización de dos ediciones de un festival de cine y feminismo. En las redes sociales también se han formado grupos, iniciativas y encuentros regulares, como los organizados por Lu Cordaro. El festival Plataforma, está centrado en la danza y en el trabajo de artistas iberoamericanos/as que viven en Berlín o Alemania, junto a personas invitadas de Latinoamérica.

Si bien el Fieber-Festival de Artistas Iberoamericanas en Berlín estaba enfocado solo en mujeres y artistas establecidas en Berlín, creo que ha sido uno de los festivales más variados y que más disciplinas ha abarcado en los últimos años. Era un espacio importante para la comunidad de artistas mujeres de Berlín, ya que agrupaba, creaba conexiones, redes y sacaba a la luz de manera más clara, la presencia de todas las artistas que viven, trabajan y crean en esta ciudad. Para las más nuevas y que hablan poco alemán o inglés, era una opción importante para empezar a crear redes en la ciudad en el ámbito artístico.

Algunas mujeres artistas que han estado en el Fieber, a su vez, han creado sus propias iniciativas, se han integrado a otras, ya tenían las suyas, o bien, navegan por las aguas de la ebullición cultural berlinesa, alemana, europea y crean puentes con sus países, o tratan de vivir, trabajar y seguir creando. Algunas hacen una pausa debido a la maternidad, otras regresan a sus países o deciden estudiar de nuevo, y algunas, siguen de manera más o menos intensa creando o abriendo nuevos espacios, dinámicas y redes. 
Figura 18. Fieber Festival, algunas artistas de la 3era edición en el patio interno del Acud, Berlín, 2015

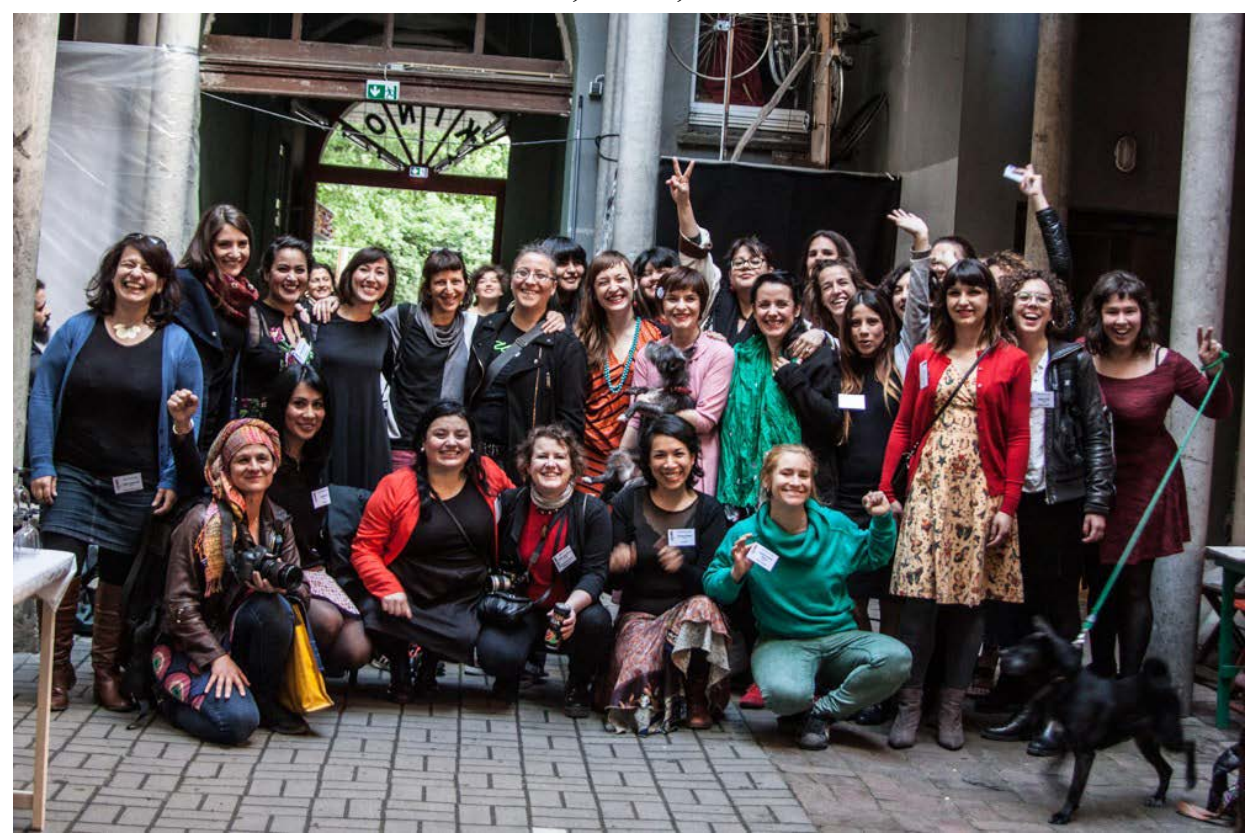

Fuente: Fieber Festival 2015, fotografía: Camila Berrio

\section{Nueva fase: Emprendimientos culturales}

Las cosas buenas también suelen tener un final. En el 2017 tuvo lugar la última edición del Fieber Festival y aunque empezamos a trabajar para la edición 2019, en ese período me quedé sin el trabajo que pagaba mis cuentas y la estabilidad laboral que tuve por varios años cambió. Tuve que iniciar un nuevo proceso en mi vida y decidí emprender nuevas aventuras laborales donde unir mi parte creativa con la parte económica y no vivir en dos mundos completamente separados. Actualmente, estoy consolidando mi empresa de fotografía comercial de retratos, objetos de arte y eventos ${ }^{19}$, retomando poco a poco mis proyectos personales artísticos, que quedaron bastante abandonados ${ }^{20}$, así como experimento en el área de animación y pintura, y escribo, entre otros.

Este proceso de cambio no habría sido posible sin el apoyo que he recibido de distintas personas y organizaciones -hay momentos en la vida, en los que hay que dejarse ayudar-. También trabajo con una asociación que apoya a artistas para posicionarse, a través de coachings grupales e individuales. Estoy conectando

19 María Rapela, Fotografía en Berlín, mariarapelafoto.com (consultado 25-01-2021)

20 María Rapela, Artista Visual, mariarapela.com (consultado 25-01-2021) 
con gente nueva, trato de hacer cosas desde una perspectiva diferentes y pienso en las estrategias que en algún momento me permitan vivir 100\% de mi trabajo, en distintos ámbitos creativos. Estoy en una etapa muy positiva de mi vida, siento que todo es posible, me siento más asentada en la ciudad y con una serie de experiencias vividas a lo largo de los años, que me han traído buenas amistades, experiencias, redes, aprendizajes, alegrías y reflexiones.

Como cierre, quiero dejar este texto, que nació durante el proceso de reflexión y escritura de este artículo, para aquellas personas que sienten que de alguna manera han perdido el rumbo en sus vidas y en su producción artística.

El arte es como un amigo invisible, que te lleva de la mano, te muestra caminos, te pone a trabajar, a crear, a jugar, a reflexionar, a cuestionarte, te pone al lado de gente maravillosa que también tiene a un amigo invisible al lado. Este amigo "el arte", te lleva a vivir situaciones creativas, te muestra algunas oportunidades y posibles caminos. Siempre está ahí, alentándote a luchar, pero no aplaude si te va bien, no te juzga si te va mal o si te has detenido por un tiempo. Este amigo, entiende que puedes tener otros intereses y preocupaciones en la vida, que necesitas de otras cosas. Si pasan meses o años, porque estás ocupado en otras cosas, no te preocupes, el arte estará sentado, durmiendo o descansando a tu lado, a veces abre un ojo para ver si te has decidido a continuar. El arte estará siempre ahí esperando que despiertes y te pongas de nuevo a trabajar. Nunca te abandonará, él te ha elegido a ti y no es posible soltar a nadie una vez que han empezado a caminar de manera conjunta.

No obstante, el arte no sabe qué hacer para que las cosas funcionen en el sistema del arte humano y ahí se requieren de otros talentos, de otro tipo de guías, que pueden cambiar según las épocas. El arte no sabe cómo marcha el dinero ni los negocios, esos temas los tenés que averiguar con otras personas, el arte mientras tanto espera, quizás se aburre, pero no te juzga, deja en tus manos que hagás lo que podás, con los recursos que tengás a tu alcance.

$\mathrm{Al}$ arte le da igual si exponés o no exponés, si te aplauden o no, si tenés éxito o no te salen las cosas, a esta amistad secreta solo le gusta verte y encontrarte trabajando para descubrir el arte de vivir la vida.

\section{Bibliografía}

bamf.de - Ministerio Alemán de Extranjería y Migración.

berlin.de - El portal oficial de Berlín dice que hay 5 escuelas/colegios que ofrecen la enseñanza del castellano como segunda lengua o que son bilingües. https://www.berlin.de/kultur-und-tickets/tipps/multikulti/ 
spanisches-berlin/2279720-3039790-spanischsprachige-schulen.html (consultado 25-01-2021)

Caso, Ángeles. Las Olvidadas. Una Historia De Mujeres Creadoras. España: Editorial Planeta, S.A., 2005.

DAS, Deutsche Auslandsschulen, https://www.auslandsschulwesen.de/Webs/ZfA/ DE/Schulnetz/DAS/Weltkarte/weltkarte_node.html (consultado 25-01-2021)

Debord, Guy. Teoría de la Deriva (1958). Texto aparecido en el \# 2 de la Internationale Situationniste. Traducción extraída de Internacional situacionista, vol. I: La realización del arte, Madrid: Literatura Gris, 1999.

Eine ganz große Koalition für die City Tax, 2012, koalition-der-freien-szene-berlin.de (consultado 25-01-2021)

Federici, Silvia. Revolución en punto cero. Trabajo doméstico, reproducción y luchas feministas. España: Ediciones Traficantes de Sueños, 2013.

Festival Independiente de Artistas Iberoamericanas en Berlín. 2011-2017, fieberfestival.com (consultado 25-01-2021)

Herrera Rapela, María Luisa. Reflexiones a partir de observaciones. Alemania, Blog: María Rapela Una tica en Berlín unaticaenberlin.blogspot.com, 2008-2021

Husvedt, Siri. El mundo deslumbrante. España: Editorial Anagrama S.A., 2014.

IFSE. Studio Berlin IIISituation Berliner Künstler*innen und Gender Gap - Estudio III sobre la situación de los artistas en Berlín y la brecha de género. Alemania: Institut für Strategieentwicklung (IFSE), Mai 2018

Lateinamerika.org - Datos de turismo alemán en Latinoamérica, 2020.

MAV, Asociación de Mujeres en las Artes Visuales de España, https://mav.org.es (consultado 25-01-2021)

Rapela, María, mariarapelafoto.com (consultado 25-01-2021)

Rapela, María, mariarapela.com (consultado 25-01-2021)

Tagespiegel, periódico local, Traducción libre, https://www.tagesspiegel.de/berlin/ neue-zahlen-zu-bevoelkerung-in-berlin-35-prozent-der-berliner-haben-migrationshintergrund/25589402.html 27-02-2020 (consultado 25-01-2021)

Alemania, América Latina y el Caribe: Lineamientos del Gobierno Federal, Ministerio de Relaciones Exteriores de Alemania, 2010. https://www.auswaertiges-amt.de/blob/1496412/14f0ce6227e6613684b599f9016f8c99/lakkonzept-span-data.pdf (consultado 02-06-2021) 
Villavicencio, Karina. "Entrevista Karina Villavicencio una artista que utiliza el cuerpo como superficie para la reflexión artística". Blog: María Rapela Una tica en Berlin, 2021, https://unaticaenberlin.blogspot.com/2021/01/ karina-villavicencio-una-artista-que.html (consultado 25-01-2021)

Wirnshofer, Josef. "Entrevista a Marke Cruse, directora de la Feria de Arte ABC y Berlin Art Week", spiegel.de, 2016. https://www.spiegel.de/consent-a-?targetUrl=https\%3A\%2F\%2Fwww.spiegel.de\%2Fkultur\%2Fgesellschaft\%2Fart-berlin-contemporary-berlin-ist-die-stadt-des-diskurses-a-1112140. html (consultado 25-01-2021) 